\title{
Thermal Stability Enhancement of Hydrogen Bonded Semicrystalline Thermoplastics Achieved by Combination of Aramide Chemistry and Supramolecular Chemistry
}

\begin{abstract}
Mikihiro Hayashi ${ }^{\dagger}$ and Francois Tournilhac ${ }^{*}$
Thermo-stability enhancement of supramolecular thermoplastics is a meaningful task to enable more application for their usage at high temperatures. An inspiration from aromatic polyamide (aramide) led us to prepare multi-block semicrystalline supramolecular polymers bearing an amorphous dicarboxylic central block and end caps composed of a hydrogen bonding unit (UDETA) and an aramide unit (NHCO-phenyl ring-OCHN). We also prepared three other semicrystalline materials to demonstrate thermal property tuning by simply varying the end caps. Thermal properties of the semicrystalline compounds, including glass transition temperature $\left(T_{\mathrm{g}}\right)$ and melting point $\left(T_{\mathrm{m}}\right)$ by differential scanning calorimetry (DSC), decomposition temperature $\left(T_{\mathrm{d}}\right)$ by thermogravimetric analysis (TGA), and softening temperature ( $T_{\text {softning }}$ ) by dynamic mechanical analysis (DMA), were systematically varied depending on thermal features of the end caps. Especially, $T_{\mathrm{m}}$ and $T_{\mathrm{d}}$ were found higher than $200{ }^{\circ} \mathrm{C}$ and $400{ }^{\circ} \mathrm{C}$, respectively, when both hydrogen bonding and aramide fragments were present. Melt viscosity investigated by rheology was lower than $1 \mathrm{~Pa} \cdot \mathrm{s}$ for each compound due to low molecular weight of the components (nearly $1200 \mathrm{~g} / \mathrm{mol}$ or less), which is desirable for practical melt processing. Interestingly, shear thinning behavior was observed only in the aramide unit incorporated compound among all compounds. This indicates highly clusterable nature of aramide fragments, which was also supported by the data of its larger flow activation energy than other compounds bearing no aramide fragments. Between $T_{\mathrm{g}}$ and $T_{\mathrm{m}}$, a large elastic plateau region was observed in DMA measurements for all compounds, despite their low molecular weight, meaning that the flexible strands are effectivelty connected into a network through crystallized end-capping groups.
\end{abstract}

\section{Introduction}

Thermoplastics are one of the representative polymeric materials that have been widely used in our daily lives since the early part of 20th century. In contrast to thermosets, thermoplastics become fluid at temperatures higher than the glass transition temperature $\left(T_{\mathrm{g}}\right)$ and the melting point $\left(T_{\mathrm{m}}\right)$ of the component polymers, which provides advantages of good processability and recyclability. ${ }^{1-4}$ Among them, semicrystalline polymer resins are superior to amorphous polymer resins in terms of mechanical strength because of the presence of stiff crystalline regions within the amorphous matrix. ${ }^{5-7}$ In addition, entanglements of the polymers further enhance the

Matière Molle et Chimie (UMR 7167 CNRS-ESPCI Paris), PSL Research University, 10 rue Vauquelin, 75005 Paris, France

E-mail: francois.tournilhac@espci.fr

+ Present address: Prof. Tokita group, Department of Chemical Science and Engineering, School of Materials and Chemical Technology, Tokyo Institute of Technology, Ookayama 2-12-1, Meguro-ku, Tokyo 152-8552, Japan

E-mail: mhayashi@nagoya-u.jp

Electronic Supplementary Information (ESI) available: Synthesis procedure of supramolecular compounds, ${ }^{1}$ HNMR analysis, FT-IR spectra, Estimation of association constants by ${ }^{1} \mathrm{HNMR}$, TGA data of the end cap molecules, DSC thermograms, Isothermal TGA data of the final compounds, Variable temperature FT-IR measurements on compound 8 and compound 6, Plots of $\ln \eta$ as a function of inverse temperatures, Tensile data of compound 6. See DOI: 10.1039/x0xx00000x mechanical strength., ${ }^{8,9}$ However, once the entanglement regime is reached, melt viscosity $(\eta)$ increases with an increase in molecular weight $(M)$ according to a power law $\eta \sim M^{\alpha}$ with a relatively large exponent value, $\alpha \approx 3.4 .^{10,11}$ Consequently, amorphous polymers that show good mechanical properties, as a rule, have a high melt viscosity (typically in the range of $10^{2} \mathrm{~Pa} \cdot \mathrm{s}$ to $\left.10^{4} \mathrm{~Pa} \cdot \mathrm{s}\right),{ }^{12}$ which can eventually be regarded as a drawback in melt processing. To address this problem, the design of supramolecular thermoplastics was identified as a major source of inspiration towards materials with non conventional flow behaviours, ${ }^{13-18}$ where the term "supramolecular" refers to the concept of "supramolecular chemistry" originally proposed by Lehn. ${ }^{19,20}$ Other than supramolecular thermoplastics, various kinds of supramolecular materials, including supramolecular rubbers or supramolecular elastomers, ${ }^{21-33}$ supramolecular polymer gels, ${ }^{34-40}$ supramolecular adhesives, ${ }^{41-43}$ etc, have been developed to attain useful functions, such as stimuliresponsiveness and self-healing ability, by utilizing the unique dynamics of supramolecular networks. ${ }^{44-51} \mathrm{~A}$ comprehensive review including both types of such networks, hydrogels and bulk materials was recently published. ${ }^{52}$

Multiblock telechelic-type polymers composed of relatively low molecular weight skeletons in the center block and hydrogen bonding units in the end blocks have been reported 
as potential components for designing supramolecular thermoplastics. In comparison with conventional thermoplastic architectures, low molecular weight skeletons can help reducing the melt viscosity while hydrogen bonding units in the end block form aggregated clusters or crystalline domains, providing good mechanical strength. Meijer and Sijbesma et al. have reported preparation of telechelic-type supramolecular polymers by using low molecular weight amorphous backbones end-capped with the strong selfcomplementary hydrogen bonding unit, ureidopyrimidinone (UPy). ${ }^{53-58}$ The materials showed polymer-like mechanical properties in the solid state (stress at break > $3 \mathrm{MPa}$ ) due to highly connected molecular structure originating from the strong dimerization of UPy units while the melt viscosity was low $\left(\sim 10^{2} \mathrm{~Pa} \cdot \mathrm{s}\right)$ because the molecular network structure connected through hydrogen bonds dissociates when the temperature is raised. Similarly, Long et al. have reported supramolecular semicrytalline polymers composed of a low molecular weight semicrystalline center block and multiple hydrogen bonding end units constructed on the basis of UPy fragments. ${ }^{59,60}$ The melt viscosity was again very low (lower than $30 \mathrm{~Pa} \cdot \mathrm{s})$, and the elongation at break and impact strength of the UPy-terminated polymer was comparable to nonhydrogen bonded polymers having more than twice $M_{n}$ of the UPy-terminated polymer. In addition to these reports on designs of supramolecular thermoplastics, there are several studies describing the importance of crystallinity of hydrogen bonding groups on the bulk properties both at the solid and molten states. ${ }^{61-64}$ The key point is that crystallization of hydrogen bonding groups or other parts of the molecules affects connectivity and the degree of long-range order of the nano-structure. Most interestingly, it was shown that using the same telechelic backbone, moderate $\mathrm{H}$-bonding end-groups can bring superior mechanical properties than stronger ones, provided crystallization of end-groups is involved. ${ }^{62}$ Based on these fundamental studies, recently, our research group reported another molecular design of supramolecular thermoplastics composed of telechelic multiblock molecules bearing hydrogen bonding units in the end blocks and an alternation of amorphous and crystallizable blocks in the middle, ${ }^{65}$ where the material attained highly ordered nanostructure and additional connectivity through nano-phase separation and crystallization of both hydrogen bonding groups and middle blocks. Thanks to the well-ordered nanostructure, high mechanical strength (stress at break in the tensile tests > $10 \mathrm{MPa}$ ) was achieved while the materials flowed like a liquid oil (melt viscosity $<1.0 \mathrm{~Pa} \cdot \mathrm{s}$ ) in the molten state due to low molecular weight of the components.

Another very desirable goal is to design supramolecular thermoplastics with $T_{\mathrm{m}}$ as high as possible $\left(200-300{ }^{\circ} \mathrm{C}\right)$ and no degradation in the molten state. Although there have been various studies on supramolecular thermoplastics as described above, achieving high thermal stability $\left(T_{\mathrm{m}}>200{ }^{\circ} \mathrm{C}\right.$ or decomposition temperature $T_{\mathrm{d}}>400{ }^{\circ} \mathrm{C}$ ) has been still challenging. This should be because there is a limitation of thermal and oxidative stability of hydrogen bonding units, which prevents their usage at very high temperatures. For enhancement of the thermal stability to widen their application range, we attained an inspiration from aromatic polyamides, so-called aramides. Aramides have a molecular structure of multiple aromatic rings continuously connected through amide bonds, that is, -[CO-Ph-OCNH-Ph-NH]- as the repeating units. The polymer chains have higher rigidity due to intermolecular hydrogen bonding between amide-amide moieties and $\pi-\pi$ stacking in the polymer backbone, which induces high thermal stability (e.g., $T_{\mathrm{m}} \gg 400^{\circ} \mathrm{C}$ ) as well as great mechanical strength. ${ }^{66-71}$ Good examples which described effects of aramide segments incorporation into polymer chains on the thermal properties were reported by Gaymans et al.; they designed an ABA triblock copolymer bearing multiple aramide segments in the end blocks, where the copolymer attained higher $T_{\mathrm{m}}\left(\sim 160{ }^{\circ} \mathrm{C}\right)$ than the control polymer without the aramide segments. ${ }^{72,73}$

Here, we demonstrate further enhancement of thermal stability for semicrystalline supramolecular thermoplastics on the basis of a combination of "supramolecular chemistry" and "aramide chemistry." The strategy developed in this paper is illustrated in Figure 1. All our compounds contain the same amidoethyl-imidazolidone end groups. For this motif, the effects of supramolecular association through $\mathrm{H}$-bonds is easily observable by ${ }^{1} \mathrm{HNMR}$ (see $\mathrm{SI}$ ) and the association constants are relatively small $\left(<10^{3} \mathrm{~L} / \mathrm{mol}\right)$ as already found by $I R$ in previous studies. ${ }^{65}$ However, molecules containing this motif were also reported to form crystalline aggregates of well defined melting point. ${ }^{13,43,65}$ Here, our efforts aim at tuning the value of the melting point.

For the end blocks, we firstly prepared compound 3, a molecule composed of the hydrogen bonding unit UDETA and an aramide segment (NHCO-Ph-OCNH) adjacent to each other. Compound 3 is then reacted with 1,4-diaminobutane to form compound $\mathbf{5}$, terminated by a primary amine function, suitable to link with a carboxy-terminated central block. As the center block, we use Pripol 1009, a non-crystallizable derivative of vegetable oils, mainly composed of C36 alicyclic dicarboxylic acids. We conducted bulk condensation reaction of Pripol 1009 and compound 5, providing a semicrystalline supramolecular material (compound $\mathbf{9}$ in Figure 1). In addition, we also discuss three other supramolecular semicrystalline compounds $(\mathbf{6}, \mathbf{7}$ and 8 ) to demonstrate tunability of the thermal properties by varying the kinds of UDETA derivatives used as the end cap molecules; one is the compound composed of Pripol 1009 as central block and solely UDETA in the end blocks (compound 6). Compound 7 and compound 8 respectively contain one additional and two additional amide links in the end blocks. The thermal properties are investigated by differential scanning calorimetry (DSC) and thermogravimetric analysis (TGA), and we also conduct FT-IR measurements at different temperatures to identify the crystallized fragments in the multi-block semicrystalline material. In the end of the report, we indicate melt viscosity and mechanical properties obtained by rheological measurements and dynamic mechanical analysis (DMA), respectively, where flow activation energy is also 
estimated by viscosity measurements to figure out the degree of clusterable nature of aramide fragments.

\section{EXPERIMENTAL SECTION}

\section{Materials}

Methyl (4-chlorocarbonyl)benzoate (MCCB, FW = $198.6 \mathrm{~g} / \mathrm{mol}$ ) and 1,4-diaminobutane $(F W=88.15 \mathrm{~g} / \mathrm{mol}$ ) were purchased from $\mathrm{TCl}$ and used as received. Pripol 1009 was kindly supplied by Croda. This material is a complex mixture of polycarboxylic acids produced from coupling reaction of bio-based unsaturated fatty acids (mainly oleic and linoleic) and partially hydrogenated. Our previous reports evaluated that the empirical formula may be written as $\mathrm{HOOC}-\mathrm{C}_{34} \mathrm{H}_{x}-\mathrm{COOH}$, where $x$ ranges between 62 and 66 depending on the number of residual unsaturations. ${ }^{65}$ For the reactions, feed ratios were calculated on the basis of the acid value indicated by the manufacturer, corresponding to an equivalent weight of $285 \mathrm{~g}$ per mole of $\mathrm{COOH}$ functions.

Compound 1, UDETA (1-(2-Aminoethyl)-2-imidazolidinone, $\mathrm{FW}=129.16 \mathrm{~g} / \mathrm{mol}$ ) was kindly supplied by Arkema, and it was purified by distillation and recrystallization in toluene/chloroform mixtures before use until the melting point of $42{ }^{\circ} \mathrm{C}$ was reached. Compound 2, compound 6 and compound $\mathbf{7}$ were synthesized as previously described. ${ }^{13,65}$ Synthetic procedures and analytical data of compounds $\mathbf{2}, \mathbf{3}, \mathbf{4}$, 5, 6, 8, and $\mathbf{9}$ are detailed in SI.

\section{${ }^{1}$ H-NMR}

Attainment of the target molecule after each synthesis step was confirmed by ${ }^{1} \mathrm{H}-\mathrm{NMR}$ in a solvent composed of a $\mathrm{CDCl}_{3} / \mathrm{CD}_{3} \mathrm{OD}$ (1/1 vol. ratio) mixture. The measurements were conducted using a Bruker Avance 400 spectrometer at 400 $\mathrm{MHz}$. The NMR spectra after each reaction step are shown in Figure S1-S3 in supporting information. ${ }^{1} \mathrm{H}-\mathrm{NMR}$ was used also to observe the effects of hydrogen bonding of end-groups in $\mathrm{CCl}_{4} / \mathrm{C}_{6} \mathrm{D}_{6}$ solutions. Determination of association constants by this means is described in SI.

\section{Infrared measurements.}

All spectra were recorded in the FT-IR mode ( 32 scans) at resolution of $4 \mathrm{~cm}^{-1}$, using a standard MIR source, extended $\mathrm{KBr}$ beam splitter, and a DTGS detector. Monitoring of condensation reaction of intermediates (compounds $\mathbf{2}, \mathbf{3}, \mathbf{4}, \mathbf{5}$ ) and chemical analysis of final products (compounds $6, \mathbf{8}, \mathbf{9}$ ) were carried out on a Bruker Tensor 37 spectrometer equipped with a thermally controlled SPECAC Goldengate ATR accessory operating in the $20-200{ }^{\circ} \mathrm{C}$ thermal range. For the compounds having $T_{\mathrm{m}}$ higher than $200{ }^{\circ} \mathrm{C}$, the measurements were performed on a Bruker Tensor 27 spectrometer. Samples were molten on the top of a freshly cleaved $\mathrm{KBr}$ crystal and hold inside a Mettler FP 80 heating stage operating in the $20-$ $300^{\circ} \mathrm{C}$ range. The spectra and peak assignments for the semicrystalline compounds are provided in supporting information. Temperature dependence of IR absorption spectra was recorded on the same set-up to identify the crystallized fragments in the multi-block semicrystalline compounds. The spectra were taken between $40^{\circ} \mathrm{C}$ and $110^{\circ} \mathrm{C}$ for compound 6 , between $140{ }^{\circ} \mathrm{C}$ and $210^{\circ} \mathrm{C}$ for compound 8 , and between $70{ }^{\circ} \mathrm{C}$ and $240{ }^{\circ} \mathrm{C}$ for compound 9 from low temperature to high temperature. The spectra were recorded under $\mathrm{N}_{2}$ flow.

\section{Thermal Analysis}

DSC measurements were carried out using a DSC Q1000 analyzer (TA Instruments) operating in the T4 mode at a temperature ramp rate of $10{ }^{\circ} \mathrm{C} / \mathrm{min}$. Effects of annealing treatment on the thermal properties of final compounds were also investigated, where the annealing was applied for $1 \mathrm{~h}$ at a temperature $80{ }^{\circ} \mathrm{C}$ higher than $T_{\mathrm{g}}$. Melting point of end capping molecules, compounds $\mathbf{1}$ - $\mathbf{5}$ were also checked by DSC measurements.

TGA measurements were conducted for the final compounds and intermediates by using a TG 209 (NETZSCH) thermal analyzer operating in the ramp mode at a heating rate of $10{ }^{\circ} \mathrm{C}$ under $\mathrm{N}_{2}$ flow $(20 \mathrm{ml} / \mathrm{min})$. For the final compounds, the temperature of $5 \%$ weight loss was defined as $T_{\mathrm{d}}$. Isothermal measurements were also performed using the same equipment at $130{ }^{\circ} \mathrm{C}$ for compound 6 , at $240{ }^{\circ} \mathrm{C}$ for compound 8 , and at $300^{\circ} \mathrm{C}$ for compound 9 .

\section{Viscosity measurements}

Melt viscosity of compounds were measured by rheometry using a Physica MCR501 analyzer (Anton Paar) equipped with a cone-plane geometry of $25 \mathrm{~mm}$ diameter. Measurements were conducted in a temperature range above $T_{\mathrm{m}}$, that is, between $90{ }^{\circ} \mathrm{C}$ and $130^{\circ} \mathrm{C}$ for compound 6 , between $160^{\circ} \mathrm{C}$ and $190{ }^{\circ} \mathrm{C}$ for compound 7 , between $200^{\circ} \mathrm{C}$ and $240{ }^{\circ} \mathrm{C}$ for compound 8 , and between $270{ }^{\circ} \mathrm{C}$ and $300{ }^{\circ} \mathrm{C}$ for compound 9. Note that isothermal TGA measurement at the highest measurement temperature for each sample did not reveal a significant weight loss within the time scale of the measurements.

\section{Dynamic mechanical analysis}

DMA measurements were performed using a Q800 DMA analyzer (TA Instruments) in the film tension geometry at a frequency of $1 \mathrm{~Hz}$. The temperature range was between $0{ }^{\circ} \mathrm{C}$ and $100{ }^{\circ} \mathrm{C}$ for compound 6 , between $10{ }^{\circ} \mathrm{C}$ and $200{ }^{\circ} \mathrm{C}$ for compound 8 , and between $20^{\circ} \mathrm{C}$ and $250{ }^{\circ} \mathrm{C}$ for compound 9 with a heating ramps rate of $3^{\circ} \mathrm{C} / \mathrm{min}$. Rectangular samples of $5 \mathrm{~mm} \times 2 \mathrm{~mm}$ cross section and about $10 \mathrm{~mm}$ length were used for the tests. The samples were annealed for $1 \mathrm{~h}$ at a temperature $80^{\circ} \mathrm{C}$ higher than $T_{\mathrm{g}}$ before measurements.

\section{RESULTS}

\section{Synthesis of end-capping molecules}

The general synthetic pathway utilized in this work is sketched in Figure $\mathbf{1}$ (see also the details in Schemes S1 to S3). The starting point of all compounds is UDETA (compound $\mathbf{1}$ ). 
Extended end capping molecules 2-5 with an increasing number of amide units are generated from compound 1 by successive single monomer condensations. Thus, following a previously described procedure, compound 1 was condensed with an excess of dimethyl adipate in the absence of solvent, giving rise to methanol and a mixture of mono- and diaminolysis derivatives as well as unreacted starting material. Using a 10-fold excess of dimethyl adipate favours production of the monoaminolysis product, compound 2 . Further purification by distillation of unreacted diester and washings permits to obtain pure compound 2 (Figure S2). Then compound $\mathbf{4}$ was obtained by reacting compound $\mathbf{2}$ with a large excess of 1,4-diaminobutane (which played both parts of reagent and solvent) and subsequent isolation of the monoadduct. In case of the aramide end cap synthesis, attempts to obtain compound $\mathbf{3}$ in a similar manner to the synthesis of compound $\mathbf{2}$, that is, reaction of UDETA and large excess of dimethyl terephtalate (DMT), failed due to low reactivity of methyl ester linking to aromatic and sublimation of DMT, which invariably resulted in the occurrence of undesirable side reactions providing unidentified aromatic NMR signals. On the other hand, compound $\mathbf{3}$ was obtained in a good yield by solution condensation with UDETA and a monoacyl chloride terephtalic derivative (MCCB) at 1:1 stoichiometry, giving rise to an NMR-pure material without the need of massive isolation procedure (Figure S1). Compound 5 was obtained from the reaction between 1,4-diaminobutane and compound $\mathbf{3}$ in the similar way to the synthesis of compound $\mathbf{4}$ from compound $\mathbf{2}$.

\section{Condensation reactions}

Compounds 1, 4 and 5, which are terminated with $\mathrm{NH}_{2}$ functions, were reacted with Pripol 1009, a dicarboxylic acid derivative of vegetable oils, in the absence of solvents. Compound 2, which is terminated with methyl ester, was reacted with Priamine 1074, where Priamine 1074 has the same type of skeleton as Pripol 1009 but terminated with $\mathrm{NH}_{2}$ functions. Bulk condensation reactions were carried out typically at $160-200{ }^{\circ} \mathrm{C}$ in the presence of a nitrogen gas flow. Bulk condensation to produce compound 9 was conducted and completed with a good conversion, although some adaptations with respect to reaction temperature and vacuum set-up were necessary to conduct the condensation throughout the series: compound $\mathbf{1}$ is rather volatile and requires lower temperature and gas flow instead of vacuum in the condensation reaction with Pripol 1009 whereas compound 9 requires high temperature because of its components' high melting temperature and accepts the use of vacuum. Note that the reaction, in all cases, was conducted with the addition of a slight excess of the precursor in terms of functional mole ratio in order to compensate the evaporation. This method worked well to achieve good conversion (nearly 100\%), which was supported by ${ }^{1} \mathrm{H}-\mathrm{NMR}$ measurements (NMR spectra are provided in Figure S1 to S3). It should be also mentioned here that in NMR spectra of compound 9, small amounts of transamidation by-products were detected (please see SI, Figure S4).
As reported in the literature, ${ }^{74}$ this reaction is effectively taking place in the high temperature range, which is here required for the thermal condensation of compound $\mathbf{5}$ and Pripol 1009.

\section{Thermal properties}

\section{DSC measurements and TGA.}

The melting endotherms of precursors, compound 1-5, are depicted in Figure 2a (the values of $T_{\mathrm{m}}$ are also indicated in Figure $2 \mathrm{a}$ and Table 1). The melting point is $42^{\circ} \mathrm{C}$ for compound $1,86^{\circ} \mathrm{C}$ for compound 2 and $145^{\circ} \mathrm{C}$ for compound 4; evidently, the melting point increases with successive monomer condensations. The same tendency is observed to a much larger extent in the aromatic series. Starting from UDETA $\left(T_{\mathrm{m}}=\right.$ $42^{\circ} \mathrm{C}$ ), the melting point jumps to $171^{\circ} \mathrm{C}$ for compound 3 and then $184^{\circ} \mathrm{C}$ for compound 5 . This suggests that the attachment of an aromatic unit adjacent to UDETA brings potential to obtain crystallized materials with higher thermal stability. We also checked the decomposition behavior of these end capping molecules, and the data of TGA are shown in Figure S6. The thermal toughness of UDETA against decomposition was significantly enhanced by amidation of its amino group. Indeed, incorporation of an aramide unit next to UDETA largely affects the thermal toughness against decomposition. It was also found from the data that the initial decay of mass started at lower temperature for the molecules possessing an amino end functional group than for the ones with an ester end functional group whereas the onset of $50 \%$ weight loss was regularly shifted to higher temperatures when the number of amidelinked fragments was increased.

Figure $2 b$ represents the DSC thermograms of the final compounds (compounds 6-9), all recorded on heating after an annealing treatment of 1 hour at a temperature $80^{\circ} \mathrm{C}$ higher than $T_{\mathrm{g}}$. The values of $T_{\mathrm{g}}$ and $T_{\mathrm{m}}$ are summarized in Table 1 . It is evident that both $T_{\mathrm{g}}$ and $T_{\mathrm{m}}$ are strongly influenced by the thermal nature of the end-capping group. Values of $T_{\mathrm{g}}$ were $-5{ }^{\circ} \mathrm{C}$ for compound $6,1{ }^{\circ} \mathrm{C}$ for compound $7,21{ }^{\circ} \mathrm{C}$ for compound 8 , and $43{ }^{\circ} \mathrm{C}$ for compound 9 . The order of $T_{\mathrm{g}}$ was thus following the order of melting points of their respective precursors, compounds $\mathbf{1}, \mathbf{2}, \mathbf{4}$ and 5, suggesting the propensity towards crystallization of the end block fragment has an impact on the segmental movement of the molecules. Values of $T_{\mathrm{m}}$ were $83^{\circ} \mathrm{C}$ for compound $6,164^{\circ} \mathrm{C}$ for compound 7, $199{ }^{\circ} \mathrm{C}$ for compound 8 , and $225^{\circ} \mathrm{C}$ for compound $\mathbf{9}$, which was again following the order of $T_{\mathrm{m}}$ of the end capping molecules. Remarkably, $T_{\mathrm{m}}$ of compound 9 was much higher than $200{ }^{\circ} \mathrm{C}$ due to high crystallizable nature of the aromatic fragment originating from intermolecular hydrogen bonding between the amide-amide moieties and $\pi$-stacking of phenyl rings. The melting peak of compound 9 was broad unlike these of other compounds, which should be relevant to the fact that compound 9 contains small amount of by-product caused by transamidation as mentioned above. Thermograms for the unannealed samples are presented in the SI, Figure S7a. Evidently, the $T_{\mathrm{g}}$ and $T_{\mathrm{m}}$ values are weakly dependent on the thermal history but annealing makes the shape of the melting peak smoother (compare the thermograms in Figure S7a). The 
thermograms on cooling are also provided in Figure S7b. In contrast to compound $\mathbf{6}$, which hardly shows crystallization on cooling, compounds 8 and compound $\mathbf{9}$ regularly show crystallization exotherms on cooling.

The decomposition temperature $\left(T_{\mathrm{d}}\right)$ of the compounds investigated by TGA was also affected by the kinds of endcapping groups (see Figure 3 and Table 1), where $T_{d}$ was defined at the temperature of $5 \%$ weight loss. The order of $T_{\mathrm{d}}$ was again substantially following that of $T_{\mathrm{m}}$ of the end caps, and especially, $T_{\mathrm{d}}$ of compound 9 exceeded $400{ }^{\circ} \mathrm{C}$. We also tested the weight loss of compound $\mathbf{9}$ by isothermal measurements at high temperature $\left(300{ }^{\circ} \mathrm{C}\right)$ as shown in Figure S8. The weight loss was almost negligible within the long measurement time (5h).

\section{Variable temperature IR spectroscopy}

DSC measurements indicate that compounds 6 - 9 are semicrystalline materials. Variable temperature IR measurements have been carried out to identify the crystallized fragments in the multi-block materials with a particular attention to aromatic fragments. Figure 4a represents the temperature dependence of IR spectra for compound 9 in the carbonyl stretching vibration region (from $1500 \mathrm{~cm}^{-1}$ to $1850 \mathrm{~cm}^{-1}$ ). At a temperature much lower than $T_{\mathrm{m}}$ three distinctive peaks are observed at $1684 \mathrm{~cm}^{-1}, 1637 \mathrm{~cm}^{-1}$ and $1626 \mathrm{~cm}^{-1}$. The first two are already present in the infrared spectra of compounds $\mathbf{6}$ and $\mathbf{8}$ (see $\mathrm{SI}$ ), and they respectively correspond to the $\mathrm{C}=\mathrm{O}$ stretching vibrations of imidazolidone and amide fragments in the solid phase. Above the melting point, these originally sharp peaks turn to broad absorption bands with maxima around $1705 \mathrm{~cm}^{-1}$ and $1657 \mathrm{~cm}^{-1}$, attributable to the same vibrators in the liquid state. The peak at $1626 \mathrm{~cm}^{-1}$ is not present in any other compounds studied here except compound $\mathbf{9}$ in the solid phase. Clearly, this vibration is characteristic of crystallized terephtalic diamide units. Above the melting point, it is shifted and no longer distinguishable from other amide $v_{\mathrm{C}=0}$ vibrations (around 1640-1680 $\mathrm{cm}^{-1}$ ). A similar shift was reported and used to measure crystallinity in related aramide compounds. ${ }^{75,76}$ In parallel to the shift of $v_{\mathrm{C}=\mathrm{O}}$ vibrations of amide and imidazolidone fragments, the peak from N-H bending absorption ( $\sigma_{\mathrm{N}-\mathrm{H}}$, amide II) also shifts from $1544 \mathrm{~cm}^{-1}$ to 1531 $\mathrm{cm}^{-1}$ with an increase in temperatures, consistent with the overall weakening of hydrogen bonds. ${ }^{77,78}$

Changes of FT-IR spectra for compound 9 depending on temperatures at the high wave number region are shown in Figure $4 \mathrm{~b}$. The stretching vibration peak of hydrogen bonded $\mathrm{N}-\mathrm{H}\left(v_{\mathrm{H}-\text { bonded } \mathrm{N}-\mathrm{H}}\right)$ was observed at $3302 \mathrm{~cm}^{-1}$ at $70{ }^{\circ} \mathrm{C},{ }^{24}$ which was shifting to a higher wave number with an increase in temperatures, as observed for $v_{\mathrm{C}=\mathrm{O}}$ vibrations, due to dissociation of amide-amide hydrogen bonds. In addition, a shoulder peak was appearing at around $3400 \mathrm{~cm}^{-1}$ at higher temperature, which originates from free $\mathrm{N}-\mathrm{H} .{ }^{24}$ On the other hand, the position of symmetric and asymmetric stretching vibrations absorptions of $\mathrm{CH}_{2}$ observed at $2856 \mathrm{~cm}^{-1}$ and 2925 $\mathrm{cm}^{-1}, 8$ respectively, which were mainly from the fatty acid skeleton, remain remarkably constant at any temperature. Therefore, we found from these results that only the end parts are involved in the crystallization while the central part remains substantially amorphous, as sought by design. Indeed, similar results were obtained for compound 8 and compound 6 (see Figure S9 and S10).

\section{Mechanical properties}

\section{Melt viscosity}

Melt viscosity was measured by rheometry as a function of the shear rate. Figure 5a-d represent the data for compound 6 - 9, respectively. Melt viscosity of all compounds was lower than 1.0 Pa.s at temperatures enough higher than their $T_{\mathrm{m}}$ (the values at the temperature $40{ }^{\circ} \mathrm{C}$ higher than the $T_{\mathrm{m}}$ are summarized in Table 1 ), showing an advantage for practical melt processing. Interestingly, compound 9 bearing aromatic amide fragments showed shear thinning behavior while the other compounds behaved as Newtonian fluids. Note that the shear thinning behavior of compound 9 was observed in the measurements both from high shear rate to low shear rate and the reverse, meaning that the shear thinning behavior was not due to progress of cross-linking or other side reactions at high temperatures.

Similar behavior was also observed previously in the study reported by Gaymans et al. for the polymers bearing multiple aramide fragments in the end blocks of triblock copolymers. According to this study, ${ }^{72,73}$ the shear thinning behavior of the aramide fragments incorporated polymers was explained as follows; aramide fragments remain associated in the form of clusters even in the molten state due to the high clusterable nature. The clusters are gradually being dissociated under application of shear, which induces a lowering of viscosity (schematic explanation is provided in reports from Gaymans et al.). ${ }^{72,73}$ To characterize the clusterable nature of aramide fragments, we measured on Arrhenius plots the apparent activation energy $\left(E_{\mathrm{a}}\right)$ of the Andrade equation, $\eta=A \exp \left(E_{a} /\right.$ $R T$ ), where $A$ is a constant, $\eta, R$, and $T$ denote viscosity, the gas constant, and the absolute temperature, respectively. ${ }^{5}$ Values of $E_{a}$, which were determined from the slope of the linear relationship between $\ln \eta$ and $1 / T$ as shown in Figure S11, are plotted as a function of the shear rate in Figure $5 \mathrm{e}$ (three representative shear rates were chosen for the plots). The $E_{a}$ values for compound $\mathbf{9}$ was significantly higher than those for other compounds at any shear rate. Considering the difference of molecular structures among three compounds, the high $E_{a}$ for compound $\mathbf{9}$ should be derived from aggregation in the melt. Notably, $E_{a}$ of compound $\mathbf{9}$ was clearly decreasing with an increase in shear rates, suggesting breaking up of the aggregates in the shear, ${ }^{80}$ consistent with the picture proposed by Gaymans et al. for ABA triblocks with short aramide endblocks.

\section{DMA measurements}


Figure 6 represents elastic moduli $\left(E^{\prime}\right)$ and loss tangent $(\tan \delta)$ as a function of temperatures obtained by DMA. The temperature having the maximum point of $\tan \delta$ at a low temperature region can be assigned to the $\alpha$-relaxation temperature $\left(T_{\alpha}\right)$, related to the onset of segmental motion. Therefore, the order of $T_{\alpha}$ was consistent with the order of $T_{\mathrm{g}}$ obtained by DSC. It should be noted that a stable plateau region was observed for compound $\mathbf{9}$ and compound $\mathbf{8}$ in a wide temperature range, despite the molecular mass of these compounds are merely around $1200 \mathrm{~g} / \mathrm{mol}$ or less, meaning that formation of crystalline domains provided good chain connectivity. The elastic moduli in the plateau region of compound $\mathbf{8}$ and compound $\mathbf{9}$ were in the same order (several hundred $\mathrm{MPa}$ ), since the fraction of crystalline end cap molecules in the chain is similar to each other on the basis of the formula mass of each fragment. The softening temperatures ( $T_{\text {softning }}$ ) defined at the inflection point in $\tan \delta$ curves, where $E^{\prime}$ starts dropping, were approximately $52{ }^{\circ} \mathrm{C}$ for compound 6, $187{ }^{\circ} \mathrm{C}$ for compound 8, and $205{ }^{\circ} \mathrm{C}$ for compound 9, where these temperatures were nearly consistent with their $T_{\mathrm{m}}$. Therefore, this tendency indicates that melting of the end group domains induced the collapse of the network structures as we designed.

\section{Tensile properties}

The mechanical properties of compound $\mathbf{6}$ at large deformation are reported in SI (figure S12). Compound 7, 8, and 9 were too brittle to be characterized by tensile tests. At room temperature and using a stretching rate of $2 \mathrm{~mm} / \mathrm{min}$, compound 6 shows a Young modulus of about $25( \pm 5) \mathrm{MPa}$, an elongation at break of about $10 \%$, and a stress at break of about $2 \mathrm{MPa}$. Notably, the mechanical test also revealed the occurence of the necking phenomenon very much like that observed in semicrystalline polymers. ${ }^{82}$

\section{DISCUSSION}

The synthetic strategy presented in this work pursued three goals: 1 ) to create new materials from common building blocks by ways of step polymerization that permit to control the sequence of monomers and to envision a scale up, 2) to obtain compounds with very good heat resistance, i.e., softening and degradation temperatures both high, and 3) to offer new compromises in terms of mechanical properties versus melt viscosity by supramolecular chemistry.

The proposed molecular designs are based on the hydrogen bonding molecule UDETA, which has been already widely studied in our laboratory, and on conventional repeat units of condensation plastics. For achieving transition temperatures as high as possible, our basic strategy is to build a range of end-capping crystallizable molecules increasingly extended by concatenation of diamine and diacyl fragments linked to each other via amide bridges.

Indeed, amides bridges, which readily lend themselves to hydrogen bonding and crystallization, are the basic units ensuring specific intermolecular association in polyamides. The idea is to impart similar effects in small molecule aggregates. The chemistry that we utilize to synthesize extended endcapping molecules is basically a succession of single monomer condensations. In case of the synthesis of compound $\mathbf{2}$ from UDETA, a large excess of monomer is used to prevent reaction at both sides of dimethyl adipate, which would produce unwanted symmetrical compound. Advantageously, this also works to attain high conversion, and excess unreacted monomer (dimethyl adipate) is easily removed by distillation and small amount of symmetric by-product can be eliminated by recrystallization. Thus, starting from UDETA $\left(T_{\mathrm{m}}=42.5^{\circ} \mathrm{C}\right)$ which is a primary amine, we successively built compound 2 $\left(T_{\mathrm{m}}=86.1{ }^{\circ} \mathrm{C}\right)$ terminated with a methyl ester function, and then compund $4\left(T_{\mathrm{m}}=145^{\circ} \mathrm{C}\right)$ again terminated with a primary amine function. Evidently, presence of more numerous amide fragments in the end-capping molecule brings a higher melting point. Another quality of amides is their oxidative stability, which was also observed in this study. Specifically, we find from TGA that even though $\mathrm{NH}_{2}$-terminated molecule, such as UDETA or compound $\mathbf{5}$, tend to degrade on heating, their conversion to amides increases significantly their thermal stability.

For the proof-of-concept presented here, each of the $\mathrm{H}$ bonding molecules developed is used as the endcap to the same non-crystallizable central skeleton Pripol $1009(\mathrm{COOH}$ terminated) or Priamine $1074\left(\mathrm{NH}_{2}\right.$ terminated). In this last step, the new monomer, that is, Pripol 1009 or Priamine 1074, is not volatile and the goal this time is to form the symmetrical molecule, so we proceeded at 1:1 or slightly unbalanced stoichiometry. As shown previously, with this procedure, the final condensation reaction proceeds with high conversions (> $95 \%)$. Melting temperatures of compound $\mathbf{6}, \mathbf{7}, \mathbf{8}$, range from 83 to $199{ }^{\circ} \mathrm{C}$, varying in the same direction as those of the precursor $\mathrm{H}$-bonding compounds. The construction of the terminal $\mathrm{H}$-bonding group by sequential single monomer condensations of diacyl and diamine fragments is therefore an effective strategy towards semi-crystalline supramolecular polymers with tunable melting points.

In the aromatic series, the same synthetic strategy was not applicable without some adjustments. Because the aromatic monomers are typically less volatile than their aliphatic counterparts, it was not possible to easily eliminate an aromatic reagent used in excess; In addition, functional groups directly linked to aromatics typically have a lower reactivity. Indeed, for example, we noticed that at 1:1 stoichiometry, the aminolysis of an aromatic methyl ester stops at around $60 \%$ conversion. In particular, we tried the condensation reaction of compound 3 with Priamine 1074, but the condensation reaction never reached sufficient conversion, which is why we do not describe derivative of Priamine 1074 simply endcapped by compound $\mathbf{3}$.

To overcome the issues of low reactivity and low volatility of aromatic reagents, the synthesis of compound $\mathbf{3}$ was performed not from the parent aromatic diester (dimethyl terephtalate) but from an unsymmetrical aromatic monomer having an acyl chloride $\mathrm{COCl}$ function at one end to enable quantitative acylation of the amine in UDETA at 1:1 
stoichiometry. Then, the strategy used in the $\mathbf{2} \rightarrow \mathbf{4} \rightarrow \mathbf{8}$ sequence was adapted as described below to obtain compound 9. The methyl ester-terminated compound $\mathbf{3}$ was reacted with the aliphatic diamine, 1,4-diaminobutane. This post-functionalization conducted in the presence of a large excess of the diamine easily reached $100 \%$ conversion, and the elimination of residual diamine is performed as previously described, and compound $\mathbf{5}$ was obtained purely, according to NMR analysis.

For the final condensation reaction to obtain compound $\mathbf{9}$, the main concern is the high melting point $\left(183{ }^{\circ} \mathrm{C}\right)$ of the precursor end-capping molecule, compound $\mathbf{5}$. We firstly attempted to perform this reaction in solution, but due to the low solubility in any tested solvents we were forced to dilute ten times more than in a typical procedure ${ }^{81}$ and eventually unable to conduct precipitation purification to obtain the target product. Finally, the most effective way was to perform the reaction in bulk as was done for the synthesis of compound 8 but at higher temperature. Noticeably, above $180{ }^{\circ} \mathrm{C}$, TGA data indicate that compound 5 already starts to undergo thermal degradation (see the purple color curve in Figure S6). Nevertheless, we observed formation of the target compound with only a small amount of transamidation byproducts. As a result, including compound 9 with one aromatic amide unit at each end part into the series, we achieved wide range $\left(83-225^{\circ} \mathrm{C}\right)$ of accessible melting points by this strategy.

Next comes the question of the morphology of these semicrystalline materials. Without giving here a definitive structural study, let us examine the information provided by the analytical techniques: In DSC, we note the presence of two well-characterized signals in all cases: glass transition (at a low temperature) and melting (at a high temperature). The presence of these two signals suggests that in all cases only a portion of the molecule is crystallized, and the remaining being amorphous. These observations were confirmed by DMA, where $E^{\prime}$ firstly dropped at $\alpha$ relaxation, followed by collapse of $E^{\prime}$ near $T_{\mathrm{m}}$. Between these two points, the compounds show an elastic behavior with a storage modulus in the range of several hundreds $\mathrm{MPa}$ at $1 \mathrm{~Hz}$. This behavior suggests the existence of an elastomeric network in this temperature range wherein the soft blocks form bridges between physically crosslinked domains through aggregation of the crystallized end caps. Above the melting point, the network disunites and the material loses its elastic properties.

This picture can be confirmed by infrared spectroscopy data: The characteristic signals (amide vibrations) of endcapping groups undergo very large changes in the vicinity of melting points while those of hydrocarbons, which are mainly from the central amorphous blocks, are essentially unchanged. Thus, all of these techniques contribute to give the image of a semicrystalline physical network in which the ends of the molecules are crystallized whereas central skeletons remain amorphous at any temperature. This structure gives very contrasting mechanical properties depending on temperature below or above the melting point.

We finally emphasize here again the special rheological properties obtained on the aromatic compound. The observed shear thinning type behavior and the estimated high flow activation energy is reminiscent of associative polymers. In the present case, aggregation may result from specific interactions yet effective above $T_{\mathrm{m}}$, or more likely from microphase separation between skeletons and end groups of different nature which are certainly more incompatible in the aromatic series than in the aliphatic one.

\section{CONCLUSION}

We described the preparation concept of highly thermo-stable supramoleular semicrystalline plastics on the basis of an inspiration from aramide chemistry. We firstly prepared the end cap molecule bearing an aramide unit adjacent to a hydrogen bond unit UDETA, which was attached to carboxyterminated amorphous central block through a short bisamino linker. In addition, we discussed three other semicrystalline materials by using a same or similar central block and various end caps having different melting points. According to DSC and TGA measurements, incorporation of "only one" aramide fragment into the end group greatly enhanced thermal stability of the semicrystalline materials; $T_{\mathrm{m}}$ and $T_{\mathrm{d}}$ of the aramide incorporating compound (compound 9) was higher than $200{ }^{\circ} \mathrm{C}$ and $400{ }^{\circ} \mathrm{C}$ respectively, where these values have been barely attained for supramolecular thermoplastics merely utilizing hydrogen bonding association as far as we know. Moreover, thermal properties, including $T_{\mathrm{g}}$, $T_{\mathrm{m}}, T_{\mathrm{d}}$, and $T_{\text {softning }}$ of semicrystalline compounds were systematically tuned. Considering the relatively low association constant of hydrogen bonding on UDETA derivatives, the tuning of thermal properties was mainly derived from the crystallization ability of the various end capping groups. As we designed, the melt viscosity was lower than $1.0 \mathrm{~Pa} \cdot \mathrm{s}$ at temperatures enough higher than the $T_{\mathrm{m}}$ because of low molecular weight of the components (nearly $1200 \mathrm{~g} / \mathrm{mol}$ or less), which is highly desirable for practical melt processing. Viscosity measurements also revealed that compound $\mathbf{9}$ showed much higher flow activation energy than other compounds bearing no aramide fragment as well as shear thinning behavior. This suggests the higher clusterable nature of aramide fragments, which could lead the enhancement of the thermal stability. As for mechanical properties, the present strategy gives the way to solid materials of switchable stiffness but not the way to overcome the inherent brittleness of materials made of low molar mass components. To further improve mechanical properties, while keeping low melt viscosities, combination with already proven strategies through more sophisticated architectures ${ }^{65,72,73}$ or blending with another polymer ${ }^{43}$ are quite possible options. In addition, the concept described in this report can also be applied to other kinds of thermoplastic materials by considering softness and combination of the building blocks, and therefore this could lead further development of useful supramolecular materials with high thermal stability and improved processing thus widening of the application range of these materials. 


\section{Acknowledgement}

We thank Prof. M. Cloître and Dr. C. Soulié-Ziakovic for the fruitful advice to rheological data analyses and synthesis strategy, respectively. We also thank Prof. L. Leibler, Dr. F. Chabert and Dr. R. Agnaou for preliminary works on semicrystalline UDETA derivatives. We thank Mrs I. Marlard for her kind assistance in rheological measurements. CNRS, ESPCI are thanked for financial support. M.H. is grateful to the French Government for post-doctoral scholarship.

1 S. Yin, R. Tuladhar, F. Shi, R. A. Shanks, M. Combe and T. Collister, Polym. Eng. Sci., 2015, 55, 2899.

2 C. A. Bernardo, A. M. Cunha and M. J. Oliveira, Polym. Eng. Sci., 1996, 36, 511.

3 L. T. Lim, R. Auras and M. Rubino, Prog. Poly. Sci., 2008, 33, 820.

4 A. Brems, J. Baeyens and R. Dewil, Thermal Science, 2012, 16, 669.

5 P. C. Himenz and T. P. Lodge, Polymer Chemistry 2nd ed., CRC Press, Boca Raton, FL, 2007.

6 M. Rubinstein and R. Colby, Polymer Physics, Oxford University Press, New York, 2003.

7 N. K. Bourne, E. N. Brown, J. C. F. Millett and G. T. Gray, III, J. Appl. Phys., 2008, 103, 074902.

8 R. Seguela, Macromol. Mater. Eng., 2007, 292, 235.

9 Y. F. Men, J. Rieger and G. Strobl, Phys. Rev. Lett., 2003, 91.

10 M. Doi and S. F. Edwards, J. Chem. Soc. Faraday Trans. II, 1978, 74, 1818.

11 H. Watanabe, Prog. Polym. Sci., 1999, 24, 1253.

12 A. V. Henoy and D. R. Saini, Thermoplastic Melt Rheology and Processing, Marcel Dekker, Inc., New York, 1996.

13 D. Montarnal, F. Tournilhac, M. Hidalgo, J.-L. Couturier and L. Leibler, J. Am. Chem. Soc., 2009, 131, 7966.

14 D. J. M. van Beek, A. J. H. Spiering, G. W. M. Peters, K. te Nijenhuis and R. P. Sijbesma, Macromolecules, 2007, 40, 8464.

15 D. J. M. van Beek, M. A. J. Gillissen, B. A. C. van As, A. R. A. Palmans and R. P. Sijbesma, Macromolecules, 2007, 40 6340.

16 H. M. Keizer, R. van Kessel, R. P. Sijbesma and E. W. Meijer, Polymer, 2003, 44, 5505.

17 T. Aida, E. W. Meijer and S. I. Stupp, Science, 2012, 335, 813.

18 S. Sivakova, D. A. Bohnsack, M. E. Mackay, P. Suwanmala and S. J. Rowan, J. Am. Chem. Soc., 2005, 127, 18202.

19 J. M. Lehn, Angew. Chem., Int. Ed., 1988, 27, 89.

20 J. M. Lehn, Angew. Chem., Int. Ed., 1990, 29, 1304.

21 P. Cordier, F. Tournilhac, C. Soulie-Ziakovic and L. Leibler, Nature, 2008, 451, 977.

22 D. Montarnal, P. Cordier, C. Soulie-Ziakovic, F. Tournilhac and L. Leibler, J. Polym. Sci. Part A: Polym. Chem., 2008, 46, 7925.

23 F. Sordo, S.-J. Mougnier, N. Loureiro, F. Tournilhac and V. Michaud, Macromolecules, 2015, 48, 4394.

24 M. Hayashi, S. Matsushima, A. Noro and Y. Matsushita, Macromolecules, 2015, 48, 421.

25 M. Hayashi, A. Noro and Y. Matsushita, Macromol. Rapid Commun., 2016, 8, 678 .

26 C. Hilger and R. Stadler, Polymer, 1991, 32, 3244.

27 Y. Chen, A. M. Kushner, G. A. Williams and Z. Guan, Nature Chem., 2012, 4, 467.

28 M. Burnworth, L. Tang, J. R. Kumpfer, A. J. Duncan, F. L. Beyer, G. L. Fiore, S. J. Rowan and C. Weder, Nature, 2011, 472, 334 .

$29 \mathrm{~J}$. Li, J. A. Viveros, M. H. Wrue and M. Anthamatten, Adv. Mater., 2007, 19, 2851.
30 S. Burattini, H. M. Colquhoun, B. W. Greenland and W. Hayes, Faraday Discuss., 2009, 143, 251.

31 A. Feula, A. Pethybridge, I. Giannakopoulos, X. Tang, A. Chippindale, C. R. Siviour, C. P. Buckley, I. W. Hamley and W. Hayes, Macromolecules, 2015, 48, 6132.

32 S. Burattini, B. W. Greenland, D. Chappell, H. M. Colquhoun and W. Hayes, Chem. Soc. Rev., 2010, 39, 1973.

33 S. Burattini, B. W. Greenland, W. Hayes, M. E. Mackay, S. J. Rowan and H. M. Colquhoun, Chem. Mater., 2011, 23, 6.

34 A. Noro, Y. Matsushita and T. P. Lodge, Macromolecules, 2008, 41, 5839.

35 A. Noro, Y. Matsushita and T. P. Lodge, Macromolecules, 2009, 42, 5802.

36 A. Noro, S. Matsushima, X. He, M. Hayashi and Y. Matsushita, Macromolecules, 2013, 46, 8304.

37 A. Noro, M. Hayashi, A. Ohshika and Y. Matsushita, Soft Matter, 2011, 7, 1667.

38 M. Hayashi, A. Noro and Y. Matsushita, J. Polym. Sci., Part B: Polym. Phys., 2014, 52, 755.

39 A. Noro, M. Hayashi and Y. Matsushita, Soft Matter, 2012, 8, 6416.

40 K. P. Nair, V. Breedveld and M. Weck, Macromolecules, 2011, 44, 3346

41 C. Heinzmann, U. Salz, N. Moszner, G. L. Fiore and C. Weder, ACS Appl. Mater. Interfaces, 2015, 7, 13395.

42 C. Heinzmann, C. Weder and L. M. de Espinosa, Chem. Soc. Rev., 2016, 45, 342.

43 F. Chabert, F. Tournilhac, N. Sajot, S. Tence-Girault and L. Leibler, Int. J. Adhes. Adhes., 2010, 30, 696.

44 L. Leibler, M. Rubinstein and R. H. Colby, Macromolecules, 1991, 24, 4701.

45 E. B. Stukalin, L.-H. Cai, N. A. Kumar, L. Leibler and M. Rubinstein, Macromolecules, 2013, 46, 7525.

46 K. E. Feldman, M. J. Kade, E. W. Meijer, C. J. Hawker and E. J. Kramer, Macromolecules, 2009, 42, 9072.

47 W. C. Yount, D. M. Loveless and S. L. Craig, J. Am. Chem. Soc., 2005, 127, 14488.

48 M. Muller, A. Dardin, U. Seidel, V. Balsamo, B. Ivan, H. W. Spiess and R. Stadler, Macromolecules, 1996, 29, 2577.

49 K. Mayumi, A. Marcellan, G. Ducouret, C. Creton and T. Narita, ACS Macro Lett., 2013, 2, 1065.

50 C. L. Lewis, K. Stewart and M. Anthamatten, Macromolecules, 2014, 47, 729.

51 M. Ahmadi, L. G. D. Hawke, H. Goldansaz and E. van Ruymbeke, Macromolecules, 2015, 48, 7300.

52 L. Voorhaar and R. Hoogenboom, Chem. Soc. Rev., 2016, 45 4013.

53 R. P. Sijbesma, F. H. Beijer, L. Brunsveld, B. J. B. Folmer, J. Hirschberg, R. F. M. Lange, J. K. L. Lowe and E. W. Meijer, Science, 1997, 278, 1601.

54 B. J. B. Folmer, R. P. Sijbesma, R. M. Versteegen, J. A. J. van der Rijt and E. W. Meijer, Adv. Mater, 2000, 12, 874.

55 T. F. A. De Greef, M. J. Kade, K. E. Feldman, E. J. Kramer, C. J. Hawker and E. W. Meijer, J. Polym. Sci. Part A: Polym. Chem., 2011, 49, 4253.

56 R. F. M. Lange, M. Van Gurp and E. W. Meijer, J. Polym. Sci. Part A: Polym. Chem., 1999, 37, 3657.

57 M. M. L. Nieuwenhuizen, T. F. A. de Greef, R. L. J. van der Bruggen, J. M. J. Paulusse, W. P. J. Appel, M. M. J. Smulders, R. P. Sijbesma and E. W. Meijer, Chem. - Eur. J., 2010, 16, 1601.

58 J.-L. Wietor, A. Dimopoulos, L. E. Govaert, R. A. T. M. van Benthem, G. de With and R. P. Sijbesma, Macromolecules, 2009, 42, 6640.

59 K. Yamauchi, A. Kanomata, T. Inoue and T. E. Long, Macromolecules, 2004, 37, 3519.

60 B. D. Mather, C. L. Elkins, F. L. Beyer and T. E. Long, Macromol. Rapid Commun., 2007, 28, 1601. 
61 F. Herbst, K. Schroeter, I. Gunkel, S. Groeger, T. ThurnAlbrecht, J. Balbach and W. H. Binder, Macromolecules, 2010, 43, 10006.

62 J. Cortese, C. Soulie-Ziakovic, S. Tence-Girault and L. Leibler, J. Am. Chem. Soc., 2012, 134, 3671.

63 J.-L. Wietor, D. J. M. van Beek, G. W. Peters, E. Mendes and R. P. Sijbesmat, Macromolecules, 2011, 44, 1211.

64 X. H. Lu, C. B. He and A. C. Griffin, Macromolecules, 2003, 36, 5195.

65 Agnaou, R.; Capelot, M.; Tence-Girault, S.; Tournilhac, F.; Leibler, L., J. Am. Chem. Soc., 2014, 136, 11268.

66 J. M. Garcia, F. C. Garcia, F. Serna and J. L. de la Pena, Prog. Polym. Sci., 2010, 35, 623.

67 F. C. Prehn, Jr. and S. G. Boyes, Macromolecules, 2015, 48, 4269.

68 M. R. Bellomo, G. DiPasquale, A. LaRosa, A. Pollicino and G. Siracusa, Polymer, 1996, 37, 2877.

69 S. Ran, D. Fang, X. Zong, B. S. Hsiao, B. Chu and P. M. Cunniff, Polymer, 2001, 42, 1601.

70 Y. Ishida, M. Jikei and M. A. Kakimoto, Macromolecules, 2000, 33, 3202.

71 T. Furuzono, K. Seki, A. Kishida, T. A. Ohshige, K. Waki, I. Maruyama and M. Akashi, J. Appl. Polym. Sci., 1996, 59, 1059.

72 A. Arun and R. J. Gaymans, J. Appl. Polym. Sci., 2009, 112, 2663.

73 A. Arun, K. Dullaert and R. J. Gaymans, Polym. Eng. Sci., 2010, 50, 756.

74 A. M. Aerdts, K. L. L. Eersels, and G. Groeninckx Macromolecules 1996, 29, 1041.

75 A. Arun, R. J. Gaymans. Eur. Polym. J., 2009, 45, 2858.

76 A. Arun, R. J. Gaymans, Polymer, 2008, 49, 2461.

77 L. Li, G. Yang, Polym. Int., 2009, 58, 503.

78 Y. Chen, W. Wu, T. Himmel, and M. H. Wagner, Macromol. Mater. Eng., 2013, 298, 876.

79 R. M. Silverstein, G. C. Bassler and T. Morrill, Spectrometric identification of organic compounds 4th ed., WILEY, 1981.

80 M. Uozumi, T. Matsushita, N. Sakamoto, T. Yamazaki, K. Imaizumi, L. Li, Y. Urushihara, S. Kuwamoto, H. Masunaga, S. Sasaki, and S. Sakurai, Nihon Reoroji Gakk., 2015, 43, 77.

81 J. Cortese, C. Soulie-Ziakovic, L. Leibler, Polym. Chem., 2014, 5, 116.

82 L. H. Sperling. Introduction to Physical Polymer Science, 4th edition, Wiley-Interscience, Hoboken, N. J. 2006. 
(a)

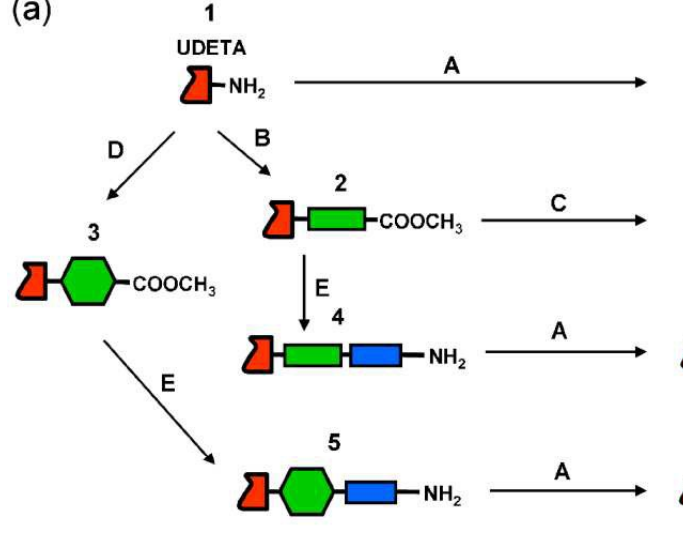

(b)

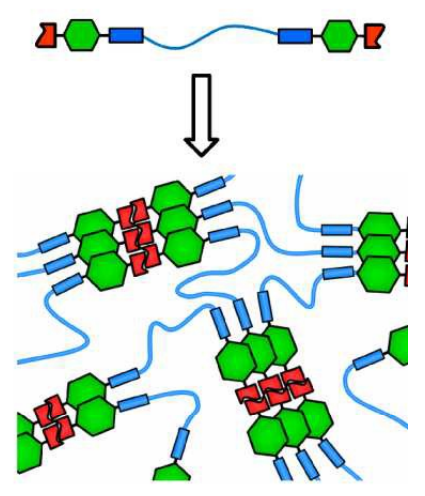

(c) compound 6



6


(e) compound 9

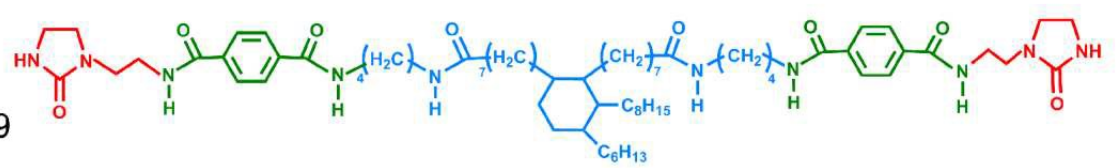

Figure 1. (a) Synthetic strategy. All steps, except (D) are performed in absence of solvent. (A) Pripol 1009; (B) dimethyl adipate (large excess); (C) Priamine 1074; (D) $\mathrm{MCCB} / \mathrm{CHCl}_{3}$; (E) 1,4-diaminobutane (large excess). Details of reaction conditions are described in SI. See ref 65 for compound 7 . (b) Supramolecular network structure expected from self-assembly of compounds 6-9, where H-bonding end-groups are aggregated in crystallized domains. Molecular structure of compound 6, compound $\mathbf{8}$, and compound 9 are shown in (c), (d), and (e), respectively. Compound 7 is described in previous work (compound a1 in ref 65). 

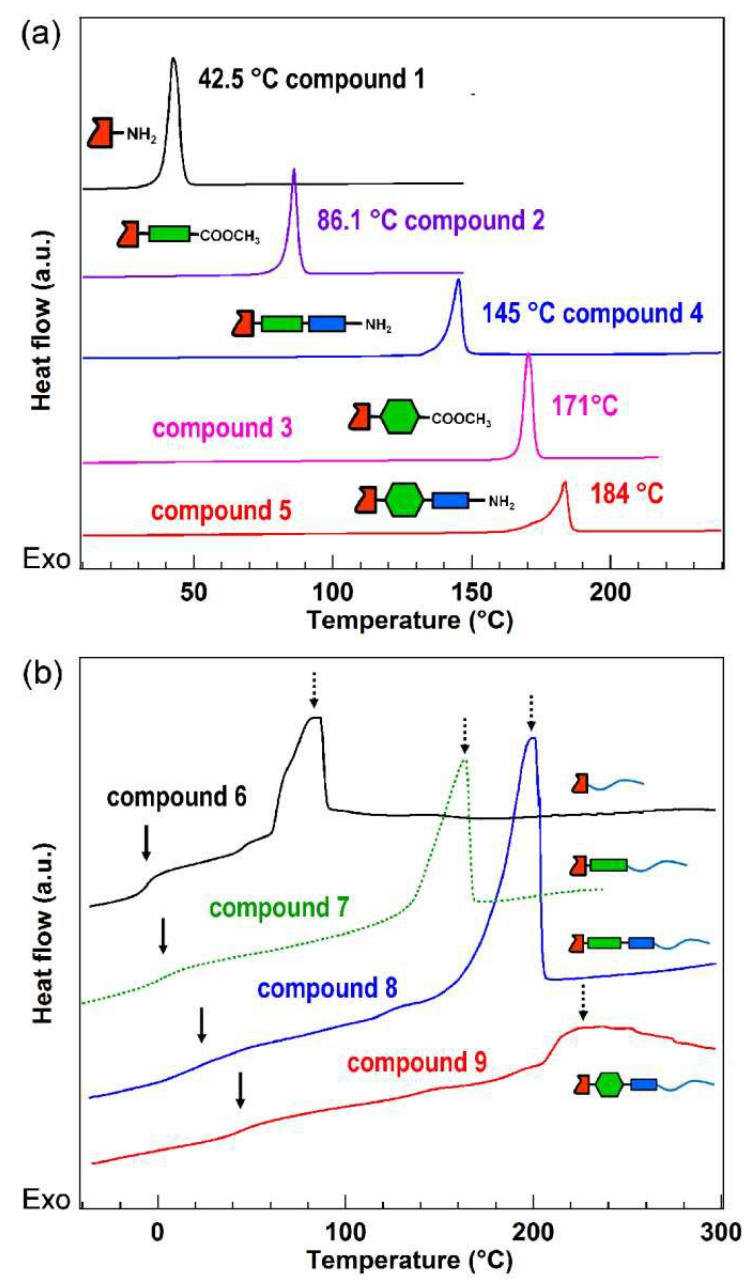

Figure 2. (a) Melting peaks of UDETA-derivatives with crystallizable fragments of increasing size. Compound 1 (black), compound 2 (purple), compound 4 (blue), compound $\mathbf{3}$ (pink), and compound $\mathbf{5}$ (red). The values represent melting points. (b) DSC thermograms on heating for compound 6 (black), compound 7, (green), ${ }^{65}$ compound $\mathbf{8}$ (blue), and compound $\mathbf{9}$ (red). Solid arrows and broken arrows represent $T_{\mathrm{g}}$ and $T_{\mathrm{m}}$, respectively.

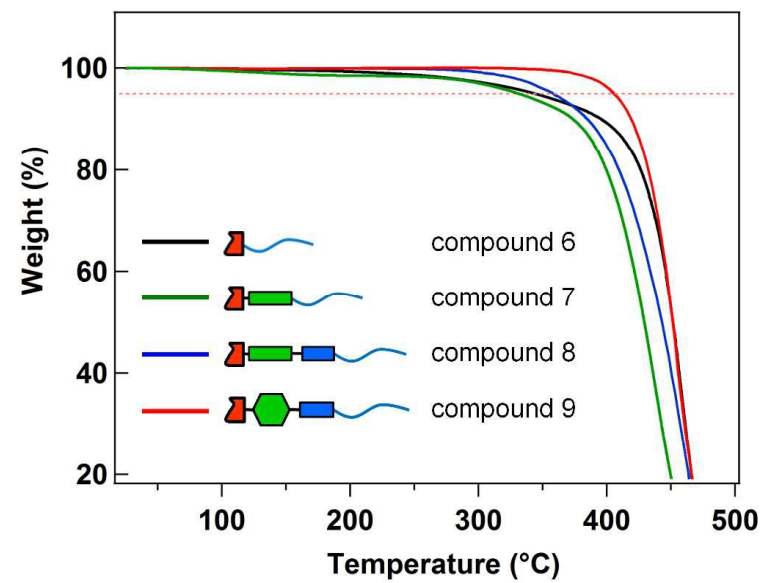

Figure 3. TGA data of compound $\mathbf{6}$ (black), compound $\mathbf{7}$ (green), compound $\mathbf{8}$ (blue), and compound $\mathbf{9}$ (red). The broken pink line represents the point at $5 \%$ weight loss.

(a)

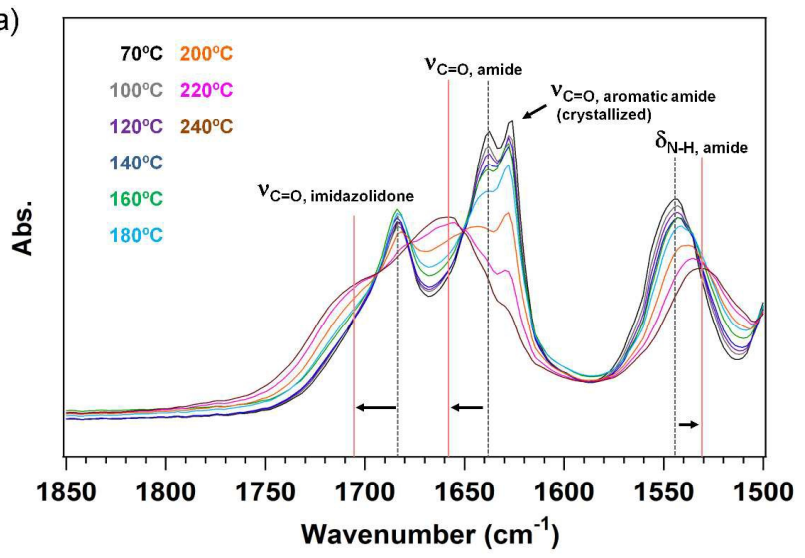

(b)

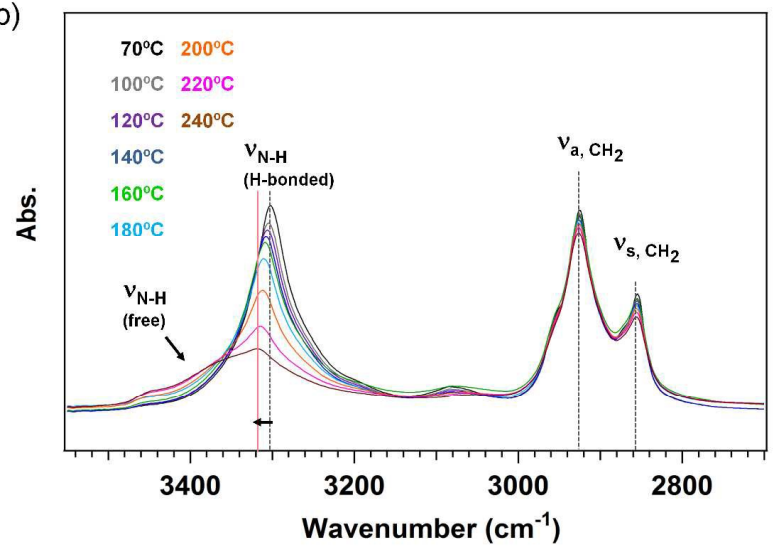

Figure 4. FT-IR spectra of compound 9 at different temperatures at (a) the carbonyl absorption region and (b) the high wavenumber region. In the spectra, broken black line and red line represent the peak position at $70{ }^{\circ} \mathrm{C}$ and $240{ }^{\circ} \mathrm{C}$, respectively, where arrows between the lines indicate the shift direction with an increase in temperatures. 

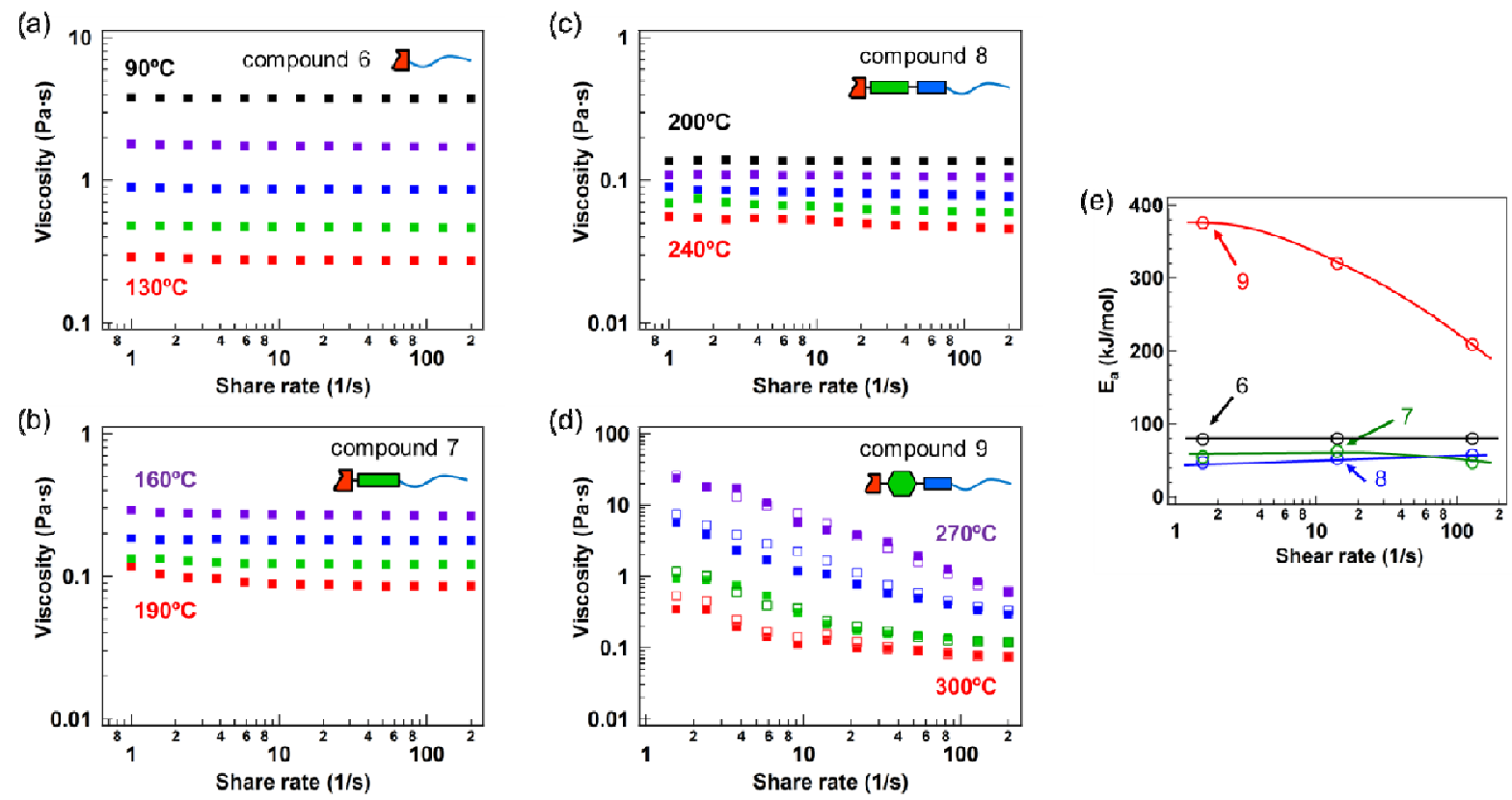

Figure 5. Melt viscosity of (a) compound $\mathbf{6}$, (b) compound $\mathbf{7}$, (c) compound $\mathbf{8}$, and compound $\mathbf{9}$ as a function of shear rates. The measurements were performed every $10^{\circ}$ C. For compound 9, the measurements were performed both from high shear rate and from low shear rate, and the data from low shear rate are plotted with filled symbols while the data from high shear rate are done with empty symbols. (e) Plots of flow activation energy, where black, green, blue, and red plots correspond to compound $\mathbf{6}$, compound $\mathbf{7}$, compound $\mathbf{8}$, and compound $\mathbf{9}$, respectively. The estimation of flow activation energy were done at three shear rates; $1.6 \mathrm{~s}^{-1}, 14 \mathrm{~s}^{-1}, 129 \mathrm{~s}^{-1}$.

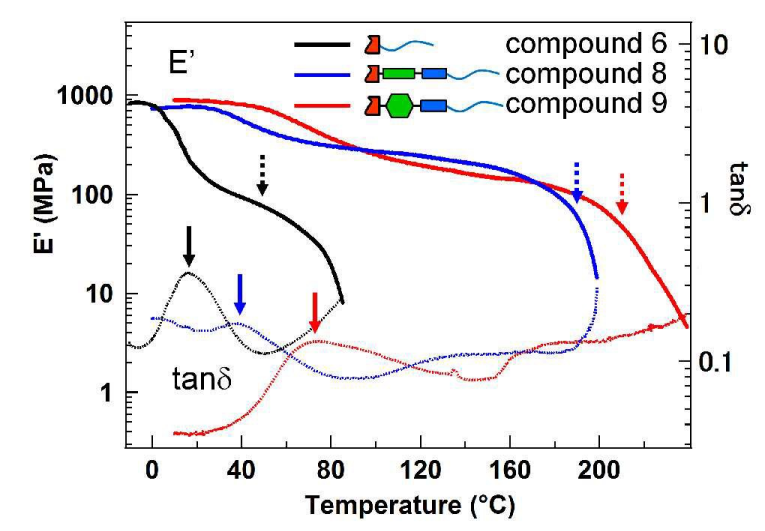

Figure 6. Elastic modulus (thick solid lines) and tan $\delta$ (broken lines) of compound 6 (black), compound 8 (blue), and compound $\mathbf{9}$ (red), as obtained by DMA. Solid and broken arrows represent $\alpha$ relaxation temperatures $\left(T_{\alpha}\right)$ and softning temperatures $\left(T_{\text {softning }}\right)$. $T_{\text {softning }}$ was defined at the inflection point in $\tan \delta$ curves. 
Table 1. Summary of thermal properties and mechanical properties for the compounds

\begin{tabular}{|c|c|c|c|c|c|c|c|c|}
\hline Code & $\begin{array}{c}T_{\mathrm{m}, \text { end cap }}{ }^{\mathrm{a}} \\
\left({ }^{\circ} \mathrm{C}\right)\end{array}$ & $\begin{array}{l}T_{\mathrm{g}}^{\mathrm{b}} \\
\left({ }^{\circ} \mathrm{C}\right)\end{array}$ & $\begin{array}{l}T_{\mathrm{m}}^{\mathrm{b}} \\
\left({ }^{\circ} \mathrm{C}\right)\end{array}$ & $\begin{array}{l}T_{\mathrm{d}}^{\mathrm{c}} \\
\left({ }^{\circ} \mathrm{C}\right)\end{array}$ & $\begin{array}{l}T_{\alpha}{ }^{\mathrm{d}} \\
\left({ }^{\circ} \mathrm{C}\right)\end{array}$ & $\begin{array}{c}T_{\text {softning }}{ }^{\mathrm{d}} \\
\left({ }^{\circ} \mathrm{C}\right)\end{array}$ & $\begin{array}{c}\eta^{\mathrm{e}} \\
(\mathrm{Pa} \cdot \mathrm{s})\end{array}$ & $\begin{array}{c}E_{\mathrm{a}}^{\mathrm{f}} \\
(\mathrm{kJ} / \mathrm{mol})\end{array}$ \\
\hline compound 6 & 42 & -5.5 & 83 & 328 & 15.4 & 52 & 0.28 & 79 / 80 / 80 \\
\hline compound 7 & $86^{\mathrm{g}}$ & $1^{g}$ & $164^{\mathrm{g}}$ & 318 & $N E^{h}$ & $N E^{h}$ & 0.08 & $55 / 63 / 47$ \\
\hline compound 8 & 145 & 21 & 199 & 352 & 41.2 & 187 & 0.05 & $47 / 52$ / 57 \\
\hline compound 9 & 184 & 43 & 225 & 408 & 70.5 & 205 & 0.84 & 374 / 319 / 209 \\
\hline
\end{tabular}

a) Melting point of end capping molecules determined by DSC; (b) Glass transition temperature $\left(T_{\mathrm{g}}\right)$ and melting point $\left(T_{\mathrm{m}}\right)$ of the compounds determined by DSC; c) Decomposition temperature measured by TGA; d) $\alpha$ relaxation temperature $\left(T_{\alpha}\right)$ and softening temperature $\left(T_{\text {softning }}\right)$, where $T_{\alpha}$ was determined at maximum point and at the inflection point in tan $\delta$ curves in DMA; e) Melt viscosity at the temperature $40^{\circ} \mathrm{C}$ (or $30^{\circ} \mathrm{C}$ in case of compound 7) higher than $T_{\mathrm{m}}$ at $129 \mathrm{~s}^{-1}$; f) Apparent activation energy for flow estimated by the Arrhenius plots of Andrade equation. The values represent the data at the shear rates of $1.6 \mathrm{~s}^{-1}, 14 \mathrm{~s}^{-1}$, and $129 \mathrm{~s}^{-1}$, arranged from left to right, respectively; (g) Values from ref $65 . ;$ (h) Not evaluated. 


\title{
Thermal Stability Enhancement of Hydrogen Bonded Semicrystalline Thermoplastics Achieved by Combination of Aramid Chemistry and Supramolecular Chemistry
}

\author{
Mikihiro Hayashi†, François Tournilhac*
}

Matière Molle et Chimie (UMR 7167 CNRS-ESPCI Paris), PSL Research University, 10 rue Vauquelin, 75005 Paris, France

Present address

$\dagger$ M.H. (Prof. Tokita group, Department of Chemical Science and Engineering, School of Materials and Chemical Technology, Tokyo Institute of Technology, Ookayama 2-12-1, Meguro-ku, Tokyo 152-8552, Japan)

1. Synthesis procedure of supramolecular compounds

2. ${ }^{1} \mathrm{HNMR}$ analysis

3. FT-IR spectra

4. Self-association in solution

5. TGA data of the end capping molecules

6. DSC thermograms

7. Isothermal TGA data of the final compounds

8. Variable temperature FT-IR measurements on compound 8 and compound 6

9. Plots of $\ln \eta$ as a function of inverse temperatures

10. Tensile data of compound 6

11. References 


\section{Synthesis procedure of supramolecular compounds}

1-1. Synthesis of compound 6

Scheme S1. Note: Pripol 1009 is a derivative of natural fatty acids, mainly composed of alicyclic dicarboxylic acids. The idealized scheme presented below is only one possible chemical structures, among others.

UDETA<smiles>NCCN1CCNC1=O</smiles>

Pripol 1009 (amorphous center part)

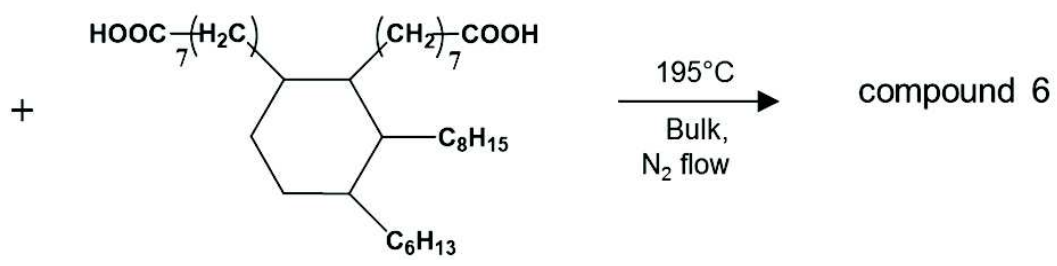

The synthesis was made as shown in Scheme S1. In a $100 \mathrm{~mL}$ three-necked flask equipped with a gas inlet and a magnetic stirring bar, Pripol (6 g, $21 \mathrm{mmol}$ of $\mathrm{COOH}$ group) was heated at $160{ }^{\circ} \mathrm{C}$ with an oil bath. UDETA (2.99 g, $23.1 \mathrm{mmol}$ of $\mathrm{NH}_{2}$ group) was added and the mixture was homogenized. The temperature of the oil bath was raised to $195{ }^{\circ} \mathrm{C}$. The condensation reaction was conducted in bulk for 90 min under $\mathrm{N}_{2}$ flow.

1-2. Synthesis of compound 8

Compound 8 was prepared according to Scheme S2.

Scheme S2.

(a)<smiles>COC(=O)CCCCC(=O)NCCN1CCNC1=O</smiles>

(b)

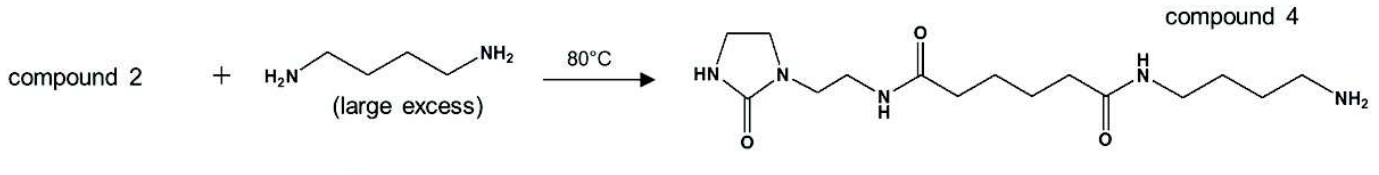

(c)

Pripol 1009 (amorphous center part)

compound 4

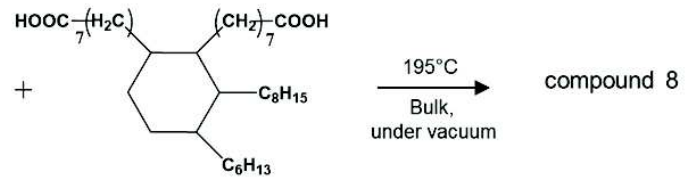

\section{1-2-1. Synthesis of compound 2.}

The synthesis was performed as already reported. ${ }^{[1]}$ 


\section{1-2-2. Synthesis of compound 4.}

Compound 4 was synthesized from compound 2: 1,4-diaminobutane (64 g, 1.5 mol of $\mathrm{NH}_{2}$ group) was put into the three-neck flask fitted with a stirring bar and a reflux condenser. Compound 2 ( $10 \mathrm{~g}, 37 \mathrm{mmol}$ of methoxy group) was then added to the flask and the resulting mixture was homogenized at $80{ }^{\circ} \mathrm{C}$. The reactive mixture was kept at $80{ }^{\circ} \mathrm{C}$ for the first $3 \mathrm{~h}$, and then the temperature was increased to $140{ }^{\circ} \mathrm{C}$ and kept for further 1 hour to complete the reaction. After the reaction, unreacted excess amine molecule was removed by precipitation of the reaction mixture into toluene. Further purification was conducted by selective washing with chloroform at $60^{\circ} \mathrm{C}$.

\section{1-2-3. Synthesis of compound $\mathbf{8}$.}

In a $100 \mathrm{~mL}$ three-necked flask equipped with a vacuum inlet and a magnetic stirring bar, Pripol 1009 (3.17 g, $11.1 \mathrm{mmol}$ of $\mathrm{COOH}$ group) was heated at $195{ }^{\circ} \mathrm{C}$ with an oil bath. Then, the end capping molecule, compound 4 ( $4 \mathrm{~g}, 12.2 \mathrm{mmol}$ of $\mathrm{NH}_{2}$ group), was added and the mixture was homogenized. The condensation reaction was conducted in bulk at $195{ }^{\circ} \mathrm{C}$ for 90 min under reduced pressure.

\section{1-3. Synthesis of compound 9}

Compound 9 was prepared according to Scheme S3.

Scheme S3.

(a)<smiles>NCCN1CCNC1=O</smiles>
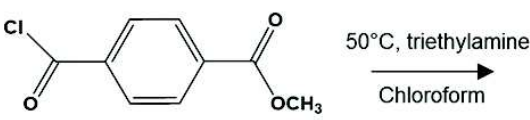<smiles>COC(=O)c1ccc(C(=O)NCCN2CCNC2=O)cc1</smiles>

(b)

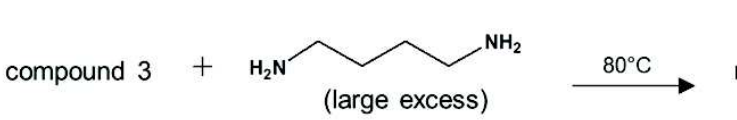

(c)

$$
\text { Pripol } 1009 \text { (amorphous center part) }
$$<smiles>NCCCCNC(=O)c1ccc(C(=O)NCCN2CCNC2=O)cc1</smiles>

compound 5
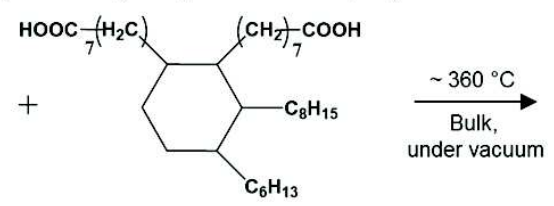

compound 9 
1-3-1. Synthesis of compound 3 .

In a $500 \mathrm{~mL}$ three necked flask equipped with a magnetic bar and a reflux condenser, $7.8 \mathrm{~g}$ UDETA $\left(60.4 \mathrm{mmol}\right.$ of $\left.\mathrm{NH}_{2}\right)$ was dissolved in chloroform $(200 \mathrm{~mL})$ at $50{ }^{\circ} \mathrm{C}$. Then, triethylamime $(25 \mathrm{~g})$ was added. A solution of $12 \mathrm{~g} \mathrm{MCCB}(60.4 \mathrm{mmol}$ of $\mathrm{COCl})$ in $150 \mathrm{~mL}$ of chloroform was added dropwise to the previous UDETA solution. The resulting mixture was stirred at $50{ }^{\circ} \mathrm{C}$ for 5 hours. After evaporation of all volatile materials, the residue was redissolved in chloroform, and the salts generated by the reaction were removed by washing with brine. After washing with clear water, drying over magnesium sulphate, compound 3 was isolated by evaporation of the solvent and then further purified by recrystallization from a methyl acetate solution.

\section{1-3-2. Synthesis of compound 5}

In a $100 \mathrm{~mL}$ three-necked flask equipped with a magnetic bar and a reflux condenser, $48 \mathrm{~g}$ of 1,4-diaminobutane (1.1 $\mathrm{mol}$ of $\mathrm{NH}_{2}$ ) were placed, together with $8 \mathrm{~g}$ of compound 3 (27 mmol of methoxy group). The mixture was homogenized by stirring at $80{ }^{\circ} \mathrm{C}$. The reaction was kept at $80{ }^{\circ} \mathrm{C}$ for the first $3 \mathrm{~h}$, and then the temperature was increased to $140{ }^{\circ} \mathrm{C}$ and kept for further 1 hour to complete the reaction. After the reaction, unreacted excess amine molecule was removed by reprecipitation of the reaction mixture into toluene. The product obtained after evaporation of toluene was further purified by selective washing with ethanol at $70{ }^{\circ} \mathrm{C}$.

\section{1-3-3. Synthesis of compound 9}

A $50 \mathrm{~mL}$ flask, fitted with a vacuum connector, a magnetic stirring bar and containing Pripol 1009 (3 g, $10.5 \mathrm{mmol}$ of $\mathrm{COOH}$ groups) was placed into a sand bath, preheated at 300 ${ }^{\circ} \mathrm{C}$ to ensure a starting temperature above $180{ }^{\circ} \mathrm{C}$. Then, the end-capping molecule, compound 5 ( $4 \mathrm{~g}, 11.5 \mathrm{mmol}$ of $\mathrm{NH}_{2}$ group), was added. The mixture was carefully put under vacuum and stirred. A homogeneous reaction mixture was rapidly obtained, and formation of gas bubbles was observed, indicating water evolution, taken as a criterion of reaction progress. Stirring was continued for 90 minutes while the temperature of the sand bath was gradually increased (up to $370{ }^{\circ} \mathrm{C}$ ) in order to permit stirring throught the reaction. At the end of gas evolution, the glass flask was pulled out from the sand bath and cooled down under vacuum. 
During cooling, crystallization was observed, resulting in a non-adhesive plastic-like material that easily unmolded from the reaction flask. 


\section{2. ${ }^{1} \mathrm{H}-\mathrm{NMR}$ analysis}

${ }^{1} \mathrm{H}-\mathrm{NMR}$ spectra at each synthesis step are shown in Figure S1 to S3 for the synthesis of the supramolecular polymers compound $\mathbf{9}$, compound $\mathbf{8}$, and compound $\mathbf{6}$, respectively. For each compound, the spectra in the high ppm region and in the low ppm region are presented in (a) and (b) panels. The measurement set-up and condition are described in the experimental section of the main text. Attribution of each signal and comparison between experimental integral values and expected integral values are provided in Tables S1 to S3, where the signal codes in the tables correspond to the same codes in the corresponding spectra. A peak from $\mathrm{CD}_{3} \mathrm{OD}$ at $3.35 \mathrm{ppm}$ was used as a reference position.

(a)

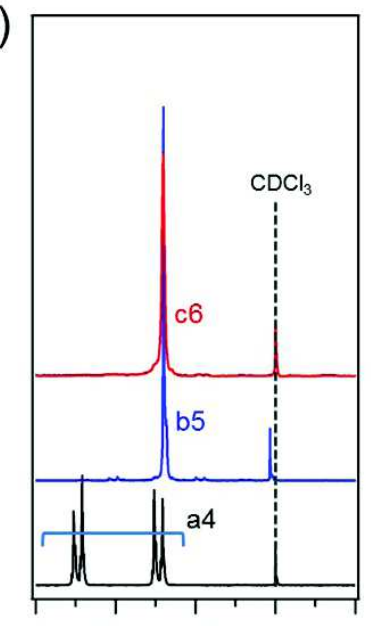

$\begin{array}{lllll}8.2 & 8.0 & 7.8 & 7.6 & 7.4\end{array}$

ppm (b)

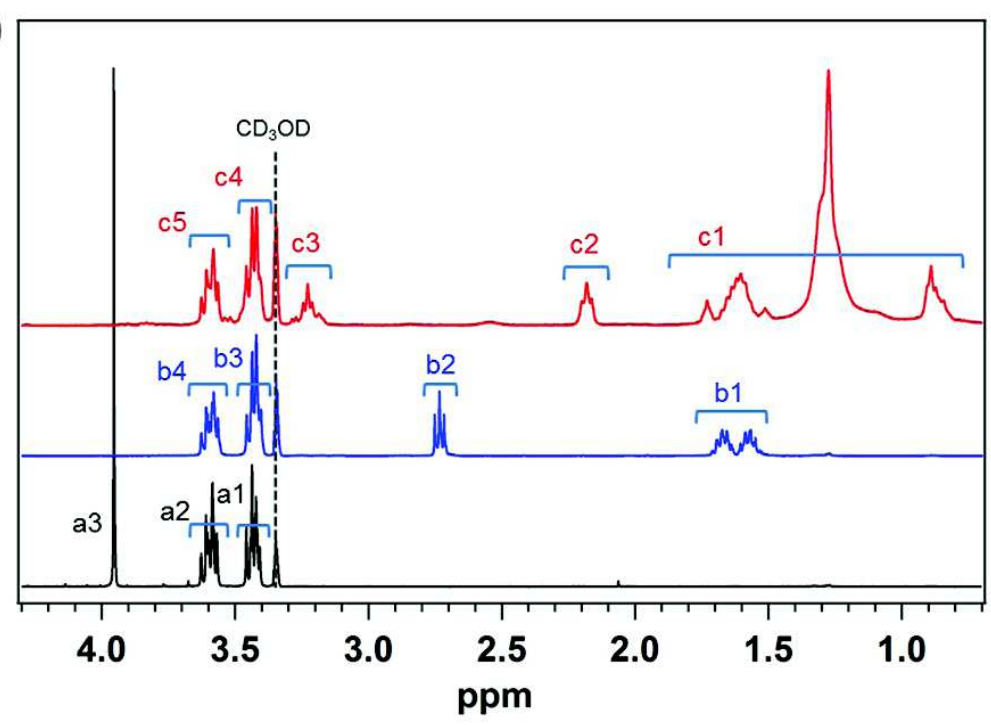

Figure S1. NMR spectra of compound 3 (black), compound 5 (blue), and compound 9 (red) in the high ppm region (a) and in the low ppm region (b). Peak assignment and integral values are provided in Table $\mathrm{S} 1$. The solvent used was mixture of $\mathrm{CDCl}_{3} / \mathrm{CD}_{3} \mathrm{OD}(1 / 1 \mathrm{vol} \%)$. 
Table S1. Attribution of signals and integral values for compound 3 (top), compound $\mathbf{5}$ (middle), and compound 9 (bottom).

\begin{tabular}{|l|l|l|c|c|}
\hline & \multicolumn{1}{|c|}{$\sigma(\mathrm{ppm})$} & \multicolumn{1}{c|}{ attribution } & integral found & expected \\
\hline a1 & $3.41-3.46$ & $\mathrm{~N}-\underline{C}_{2}$ & 4.1 & 4 \\
\hline a2 & $3.57-3.63$ & $\mathrm{~N}-\underline{H}_{2}$ (imidazolidone) & 4.1 & 4 \\
\hline a3 & 3.95 & $\mathrm{OC} \underline{\underline{H}}_{3}$ & 3 & 3 \\
\hline a4 & $7.88-8.11$ (double doublet) & $\underline{\mathrm{HC}}=\mathrm{C}$ (aromatic) & 4 & 4 \\
\hline
\end{tabular}

\begin{tabular}{|l|l|l|c|c|}
\hline & \multicolumn{1}{|c|}{$\sigma(\mathrm{ppm})$} & \multicolumn{1}{c|}{ attribution } & integral found & expected \\
\hline b1 & $1.55-1.66$ & $\mathrm{C}_{\underline{2}}-\mathrm{CH}_{2}-\mathrm{N}$ & 4.1 & 4 \\
\hline b2 & 2.72 (triplet) & $\mathrm{C}_{2}-\mathrm{NH} 2$, & 2 & 2 \\
\hline b3 & 3.41 & $\mathrm{~N}-\underline{\mathrm{H}}_{2}, \underline{\mathrm{CH}}_{2}-\mathrm{NH}-\mathrm{CO}-\mathrm{Ph}$ & 6 & 6 \\
\hline b4 & 3.57 & $\mathrm{~N}-\underline{\mathrm{H}}_{2}$ (imidazolidone) & 4.1 & 4 \\
\hline b5 & 7.87 (singlet) & $\underline{\mathrm{HC}}=\mathrm{C}$ (aromatic) & 3.9 & 4 \\
\hline
\end{tabular}

\begin{tabular}{|c|c|c|c|c|}
\hline & $\sigma(\mathrm{ppm})$ & attribution & integral found & expected \\
\hline \multirow{3}{*}{$\mathrm{c} 1$} & 0.89 & $\mathrm{C}_{\underline{H}_{3}}$ & \multirow{4}{*}{75} & \multirow{4}{*}{$62-70^{*}$} \\
\hline & 1.28 & $\mathrm{C}_{\underline{2}}$ (Pripol) & & \\
\hline & $1.49-1.7$ & $\begin{array}{l}\mathrm{C}_{\underline{\underline{H}}}-\mathrm{CH}_{2}-\mathrm{N}, \\
\mathrm{C}_{\underline{2}}-\mathrm{CH}_{2}-\mathrm{CONH}\end{array}$ & & \\
\hline & 2.54 & allylic $\mathrm{C} \underline{H}$ & & \\
\hline $\mathrm{c} 2$ & 2.18 & $\mathrm{C}_{2}-\mathrm{CO}-\mathrm{NH}$ & 4 & 4 \\
\hline $\mathrm{c} 3$ & 3.23 & $\underline{\mathrm{CH}}_{\underline{2}}$-NH-CO-alkyl & 4.2 & 4 \\
\hline $\mathrm{c} 4$ & 3.42 & $\mathrm{~N}-\underline{\mathrm{C}}_{\underline{\underline{H}}}, \underline{\mathrm{C}}_{\underline{\underline{2}}}-\mathrm{NH}-\mathrm{CO}-\mathrm{Ph}$ & 11.6 & 12 \\
\hline $\mathrm{c} 5$ & 3.58 & $\mathrm{~N}-\underline{\mathrm{H}}_{\underline{2}}$ (imidazolidone) & 8 & 8 \\
\hline c6 & 7.88 & $\underline{\mathrm{HC}}=\mathrm{C}$ (aromatic) & 7.8 & 8 \\
\hline
\end{tabular}

* depending on residual unsaturation 
(a)

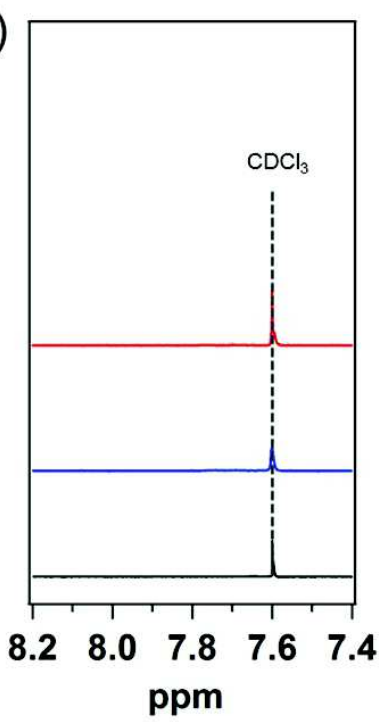

(b)

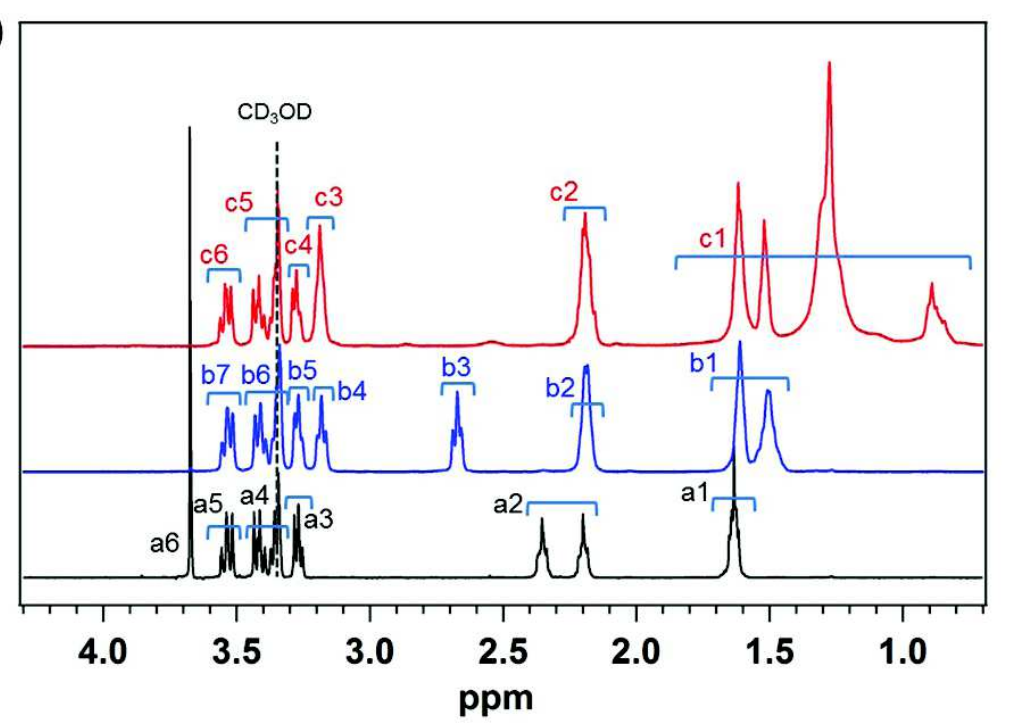

Figure S2. NMR spectra of compound 2 (black), compound 4 (blue), and compound 8 (red) in the high ppm region (a) and in the low ppm region (b). Peak assignment and integral values are provided in Table $\mathrm{S} 2$. The solvent used was mixture of $\mathrm{CDCl}_{3} / \mathrm{CD}_{3} \mathrm{OD}(1 / 1 \mathrm{vol} \%)$. 
Table S2. Attribution of signals and integral values for compound 2 (top), compound 4 (middle), and compound $\mathbf{8}$ (bottom).

\begin{tabular}{|l|l|l|c|c|}
\hline & \multicolumn{1}{|c|}{$\sigma(\mathrm{ppm})$} & \multicolumn{1}{|c|}{ attribution } & integral found & expected \\
\hline a1 & 1.63 & $\mathrm{C}_{\underline{2}}-\mathrm{CH}_{2}-\mathrm{CO}$ & 4.2 & 4 \\
\hline a2 & $2.20,2.53$ & $\begin{array}{l}\mathrm{C}_{2}-\mathrm{CO}-\mathrm{NH} \\
\underline{\mathrm{C}}_{2}-\mathrm{COOCH}\end{array}$ & 4.2 & 4 \\
\hline a3 & 3.27 & $\mathrm{~N}-\underline{\mathrm{H}}_{2}$ & 2 & 2 \\
\hline a4 & $3.34-3.41$ & $\begin{array}{l}\mathrm{N}-\underline{H}_{2} \\
\text { solvent }\end{array}$ & 4.96 & $4+\underline{\mathrm{H}}_{2}$ (imidazolidone) \\
\hline a5 & 3.54 & $\mathrm{~N}-\underline{\mathrm{C}}_{2}$ (imidazolidone) & 2.1 & 2 \\
\hline a6 & 3.68 & $\mathrm{OC} \underline{\underline{H}}_{\underline{3}}$ & 3 & 3 \\
\hline
\end{tabular}

\begin{tabular}{|l|l|l|c|c|}
\hline \multicolumn{1}{|c|}{$\sigma(\mathrm{ppm})$} & \multicolumn{1}{|c|}{ attribution } & integral found & expected \\
\hline b1 & $1.51,1.61$ & $\begin{array}{l}\mathrm{C}_{\underline{2}}-\mathrm{CH}_{2}-\mathrm{NH} \\
\mathrm{C}_{2}-\mathrm{CH}_{2}-\mathrm{CO}\end{array}$ & 7.9 & 8 \\
\hline b2 & 2.18 & $\mathrm{C}_{2}-\mathrm{CO}-\mathrm{NH}$ & 3.9 & 4 \\
\hline b3 & 2.67 & $\mathrm{C}_{\underline{2}}-\mathrm{NH}_{2}$ & 1.9 & 2 \\
\hline b4 & 3.18 & $\mathrm{C}_{2}-\mathrm{NH}-\mathrm{CO}$ & 1.9 & 2 \\
\hline b5 & 3.27 & $\mathrm{~N}-\underline{\mathrm{C}}_{2}$ & 2 & 2 \\
\hline b6 & $3.34-3.41$ & $\begin{array}{l}\mathrm{N}-\underline{\mathrm{C}}_{2} \\
\text { solvent }\end{array}$ & 5 & 2 \\
\hline b7 & 3.54 & $\mathrm{~N}-\underline{\mathrm{C}}_{2}$ (imidazolidone) & 2 & $4+$ solvent \\
\hline
\end{tabular}

\begin{tabular}{|c|c|c|c|c|}
\hline & $\sigma(\mathrm{ppm})$ & attribution & integral found & expected \\
\hline \multirow{3}{*}{$\mathrm{c} 1$} & 0.89 & $\mathrm{CH}_{\underline{3}}$ & \multirow{4}{*}{75} & \multirow{4}{*}{$70-78^{*}$} \\
\hline & 1.28 & $\mathrm{C}_{\underline{2}}$ (Pripol) & & \\
\hline & $1.52-1.62$ & $\begin{array}{l}\mathrm{C}_{2}-\mathrm{CH}_{2}-\mathrm{N}, \\
\mathrm{CH}_{\underline{\underline{ }}}-\mathrm{CH}_{2}-\mathrm{CONH}\end{array}$ & & \\
\hline & 2.54 & allylic $\mathrm{C} \underline{H}$ & & \\
\hline $\mathrm{c} 2$ & 2.19 & $\mathrm{C}_{\underline{2}}-\mathrm{CO}-\mathrm{NH}$ & 11.9 & 12 \\
\hline $\mathrm{c} 3$ & 3.19 & $\mathrm{C}_{\underline{H}_{2}}$-NH-CO-alkyl & 7.6 & 8 \\
\hline $\mathrm{c} 4$ & 3.28 & $\mathrm{~N}-\mathrm{C} \underline{\mathrm{H}}_{2}$ & 4 & 4 \\
\hline $\mathrm{c} 5$ & $3.35-3.42$ & $\mathrm{~N}-\underline{\mathrm{CH}}_{2}, \mathrm{~N}-\mathrm{C} \underline{\mathrm{H}}_{2}$ (imidazolidone) & 10.9 & $8+$ solvent \\
\hline c6 & 3.54 & $\mathrm{~N}-\underline{C}_{\underline{2}}$ (imidazolidone) & 4.1 & 4 \\
\hline
\end{tabular}

* depending on residual unsaturation 
(a)

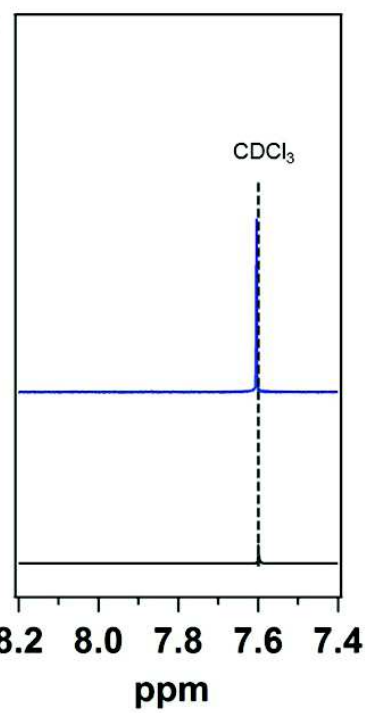

(b)

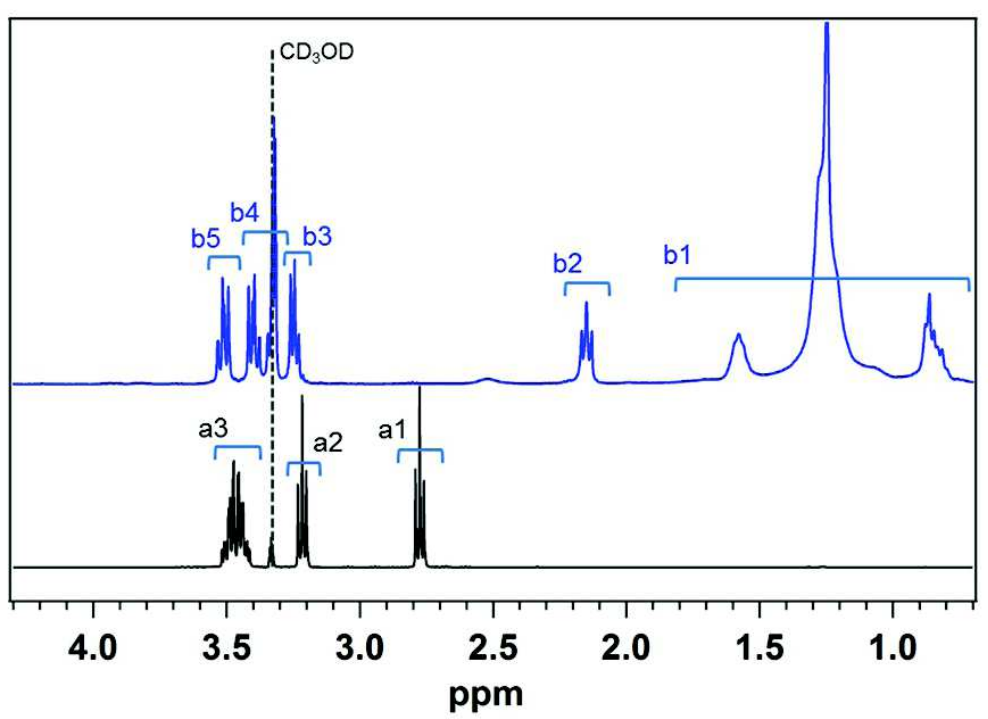

Page 23

Figure S3. NMR spectra of compound 1 (black) and compound 6 (blue) in the high ppm region (a) and in the low ppm region (b). Peak assignment and integral values are provided in Table S3. The solvent used was mixture of $\mathrm{CDCl}_{3} / \mathrm{CD}_{3} \mathrm{OD}(1 / 1 \mathrm{vol} \%)$.

Table S3. Attribution of signals and integral values for compound 1 (top) and compound 6 (bottom).

\begin{tabular}{|c|c|c|c|c|}
\hline & $\sigma(\mathrm{ppm})$ & attribution & integral found & expected \\
\hline a1 & 2.78 & $\mathrm{C}_{\underline{2}}-\mathrm{NH} 2$ & 2 & 2 \\
\hline $\mathrm{a} 2$ & 3.22 & $\mathrm{~N}-\mathrm{C} \underline{\mathrm{H}}_{2}$ & 2 & 2 \\
\hline a3 & 3.47 & $\mathrm{~N}-\mathrm{CH}_{2}$ (imidazolidone) & 4 & 4 \\
\hline
\end{tabular}

\begin{tabular}{|c|c|c|c|c|}
\hline & $\sigma(\mathrm{ppm})$ & attribution & integral found & expected \\
\hline \multirow{4}{*}{ b1 } & 0.89 & $\mathrm{C}_{\underline{3}}$ & \multirow{4}{*}{62} & \multirow{4}{*}{$54-62 *$} \\
\hline & 1.28 & $\underline{\mathrm{CH}}_{\underline{2}}$ (Pripol) & & \\
\hline & 1.61 & $\mathrm{C}_{\underline{H}}-\mathrm{CH}_{2}-\mathrm{CO}$ & & \\
\hline & 2.54 & allylic $\underline{\mathrm{CH}}$ & & \\
\hline b2 & 2.18 & $\mathrm{C}_{\underline{2}}-\mathrm{CO}-\mathrm{NH}$ & 4.1 & 4 \\
\hline b3 & 3.27 & $\mathrm{~N}-\mathrm{C} \underline{\mathrm{H}}_{2}$ & 4.1 & 4 \\
\hline b4 & $3.35-3.42$ & $\begin{array}{l}\mathrm{N}-\underline{C H}_{2} \\
\mathrm{~N}-\underline{\mathrm{CH}}_{2} \text { (imidazolidone) }\end{array}$ & 10.3 & $8+$ solvent \\
\hline b5 & 3.54 & $\mathrm{~N}-\mathrm{C} \underline{H}_{2}$ (imidazolidone) & 4 & 4 \\
\hline
\end{tabular}

* depending on residual unsaturation 


\section{Comparison of NMR spectra of compound 6 and compound 9}

Comparison of NMR spectra of compound $\mathbf{6}$ (black) and compound 9 (red) is provided in Figure S4(a). The small peaks observed in the spectrum of compound 9 at around 3.3 ppm and $3.55 \mathrm{ppm}$, which actually cannot be assigned to any protons of the target molecule, are clearly overlapped with the distinctive peaks observed in the spectrum of compound $\mathbf{6}$ as indicated with blue arrows. Considering that the condensation of compound $\mathbf{5}$ and Pripol 1009 was carried out at high temperature, the transamidation side-reaction is likely to take place, ${ }^{[2]}$ giving rise to a small quantity of end-capping groups where UDETA is linked directly to the aliphatic acyl group, as in compound $\mathbf{6}$. This consideration is consistent with the overlapping of the unassigned small peaks in the spectrum of compound 9 with those of compound 6 . The event of transamidation side-reaction in the reaction of compound $\mathbf{5}$ and Pripol 1009 is illustrated in Figure S4(b).

(a)



(b)

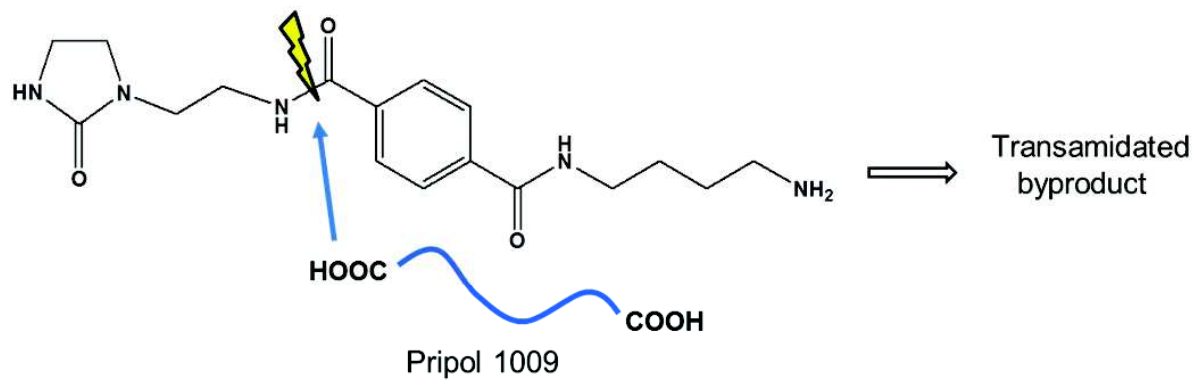

Figure S4. (a) Comparison of NMR spectra of compound 6 (black) and compound 9 (red). The peak from $\mathrm{CD}_{3} \mathrm{OD}$ is used as a reference. (b) Expected result of transamidation caused in the reaction of compound $\mathbf{5}$ and Pripol 1009 at high temperature. 


\section{FT-IR spectra}

FT-IR spectra of the final compounds, that is, compound $\mathbf{9}$, compound $\mathbf{8}$, and compound 6 are shown in Figure S5. Experimental set-up and measurement conditions are described in the experimental part of the main text. Assignments of characteristic peaks are also provided in the spectra, where abbreviations $\sigma$ and $v$ are used for bending and stretching vibration modes, respectively.



Figure S5. FT-IR spectra for compound 9 (red), compound 8 (blue), and (c) compound 6 (black). 


\section{Self-association in solution}

The effects of supramolecular association of end groups have been investigated by ${ }^{1} \mathrm{H}$ NMR. In order to cover a broad range of concentrations, the model compound S1 was synthesized as follows and studied:

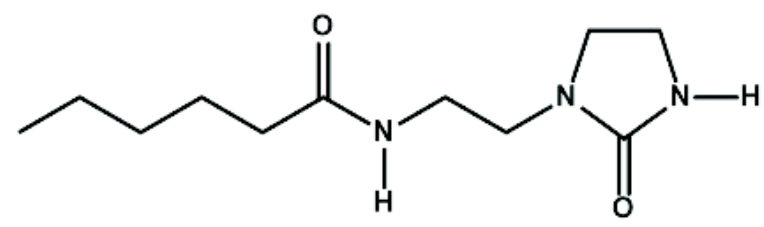

Preparation: Hexanoic acid $(23.45 \mathrm{~g}, 0.2 \mathrm{~mol})$ is condensed with UDETA $(26 \mathrm{~g}, 0,2$ mol) at $170{ }^{\circ} \mathrm{C}$ under a nitrogen atmosphere for $19 \mathrm{~h}$. After recrystallization (twice from toluene), compound $\mathrm{S} 1$ is obtained as a white solid with melting point $\mathrm{Tm}=102{ }^{\circ} \mathrm{C}(\max$. endotherm). Spectroscopic analyses are consistent with the molecular structure of compound S1.

${ }^{1} \mathrm{H}$ NMR spectra of compound $\mathbf{S 1}$ were recorded at various concentrations using a Bruker Avance 400 spectrometer and a $\mathrm{CCl}_{4} / \mathrm{C}_{6} \mathrm{D}_{6}(90: 10 \mathrm{v} / \mathrm{v})$ mixture as the solvent.

When increasing the concentration, the ${ }^{1} \mathrm{H}$ chemical shifts of both amide and imidazolidone $\mathrm{H}$-bonded protons are shifted towards higher values. In the conditions of rapid exchange, the apparent chemical shift of a partially bonded assembly obeys the classical equation: ${ }^{3}$

$$
\delta=\delta_{d}+\left(\delta_{d}-\delta_{m}\right) \frac{1-\sqrt{1+8 K c}}{4 K c}
$$

where $\delta$ is the measured averaged chemical shift, $K$ is the association constant, $c$ is the concentration, $\delta_{\mathrm{m}}$ and $\delta_{\mathrm{d}}$ are boundary chemical shift values for the monomer and dimer species, respectively.

The value of the dimerization constant of compound $\mathbf{S 1}$ at $298 \mathrm{~K}$ was obtained from the concentration dependence of the ${ }^{1} \mathrm{H}$ chemical shift of the $\mathrm{N}-\mathrm{H}$ protons of imidazolidone and amide functions in the $10^{-3}$ to $10^{-2} \mathrm{~L} \cdot \mathrm{mol}^{-1}$ range (Table S4). The fit of data using equation (S1) leads to two different association constants $K_{\mathrm{A}}$ and $K_{\mathrm{I}}$ for the amide and imidazolidone functions. The following values were found: $\delta_{\mathrm{d}}=7.08, \delta_{\mathrm{m}}=5.78 \mathrm{ppm}, \mathrm{K}_{\mathrm{A}}=60 \mathrm{~L} \cdot \mathrm{mol}^{-1}$ for the amide and $\delta_{\mathrm{d}}=5.8, \delta_{\mathrm{m}}=3.7 \mathrm{ppm}, K_{\mathrm{I}}=150 \mathrm{~L} \cdot \mathrm{mol}^{-1}$ for the imidazolidone N-H groups. This last value is close to those found in solution for other imidazolidone compounds. ${ }^{4,5}$ 
Table S4. Experimental and fitted chemical shifts as a function of total concentration of compound S1. Solvent is $\mathrm{CCl}_{4}: \mathrm{C}_{6} \mathrm{D}_{6}(90: 10 \mathrm{v} / \mathrm{v})$.

\begin{tabular}{l|l|l|l|l}
$\begin{array}{l}\text { Concentration } \\
(\mathrm{mmol} / \mathrm{L})\end{array}$ & $\begin{array}{l}d_{\mathrm{I}}(\mathrm{ppm}) \\
\text { found }\end{array}$ & $\begin{array}{l}d_{\mathrm{I}}(\mathrm{ppm}) \\
\text { calc. }\end{array}$ & $\begin{array}{l}d_{\mathrm{A}}(\mathrm{ppm}) \\
\text { found }\end{array}$ & $\begin{array}{l}d_{\mathrm{A}}(\mathrm{ppm}) \\
\text { calc }\end{array}$ \\
\hline 0.1 & - & 3.76 & - & 5.80 \\
\hline 0.25 & 3.83 & 3.84 & 5.83 & 5.82 \\
\hline 0.5 & 3.93 & 3.95 & 5.88 & 5.85 \\
\hline 1 & 4.08 & 4.11 & 5.93 & 5.91 \\
\hline 2 & 4.30 & 4.32 & 6.00 & 6.00 \\
\hline 3 & 4.48 & 4.46 & 6.07 & 6.07 \\
\hline 4 & 4.58 & 4.57 & 6.12 & 6.12 \\
\hline 5 & 4.65 & 4.65 & 6.17 & 6.17
\end{tabular}




\section{TGA data of the end capping molecules}

TGA was conducted for the end cap molecules as shown in Figure S6. The inset represents the curves within the weight range between 90 to $100 \%$. From the inset, it is evident that for compounds having a primary amine end-group: compound $\mathbf{1}$ (black), compound 4 (blue), compound 5 (purple), the onset of mass decay occurs at lower temperatures than for compounds bearing an ester end-functional group : compound 2 (green), compound 3 (light blue) and a derivative of UDETA where the $\mathrm{NH}_{2}$ function is acylated (red). Besides, the temperature where the weight drops below $50 \%$ of the initial mass seems more related to volatilization as it basically follows the order of increasing molecular weight (i.e., 1 $<\mathbf{2}<\mathbf{3}<\mathbf{4}<\mathbf{5}$ ).

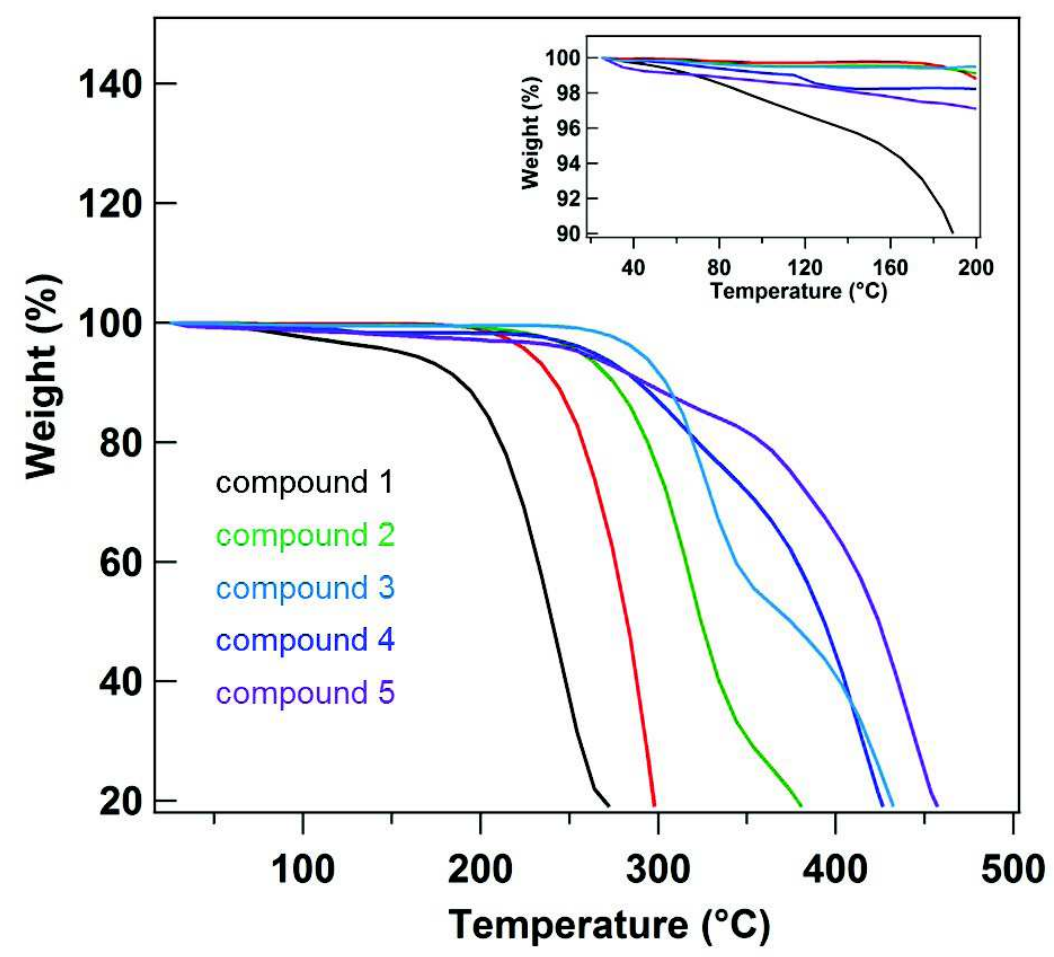

Figure S6. TGA data of end cap molecules. The colors of curves correspond with the samples in the same color. The red curve corresponds to the data of molecule synthesized by UDETA and acetic acid. The inset represents the expanded curves at initial decay of mass within the weight range between 90 to $100 \%$. 


\section{DSC thermograms}

Effects of annealing treatment on the thermograms are shown Figure S7(a). The thermograms on cooling for the annealed samples are provided in Figure S7(b). Experimental set-up and conditions are described in the experimental section of the main text.
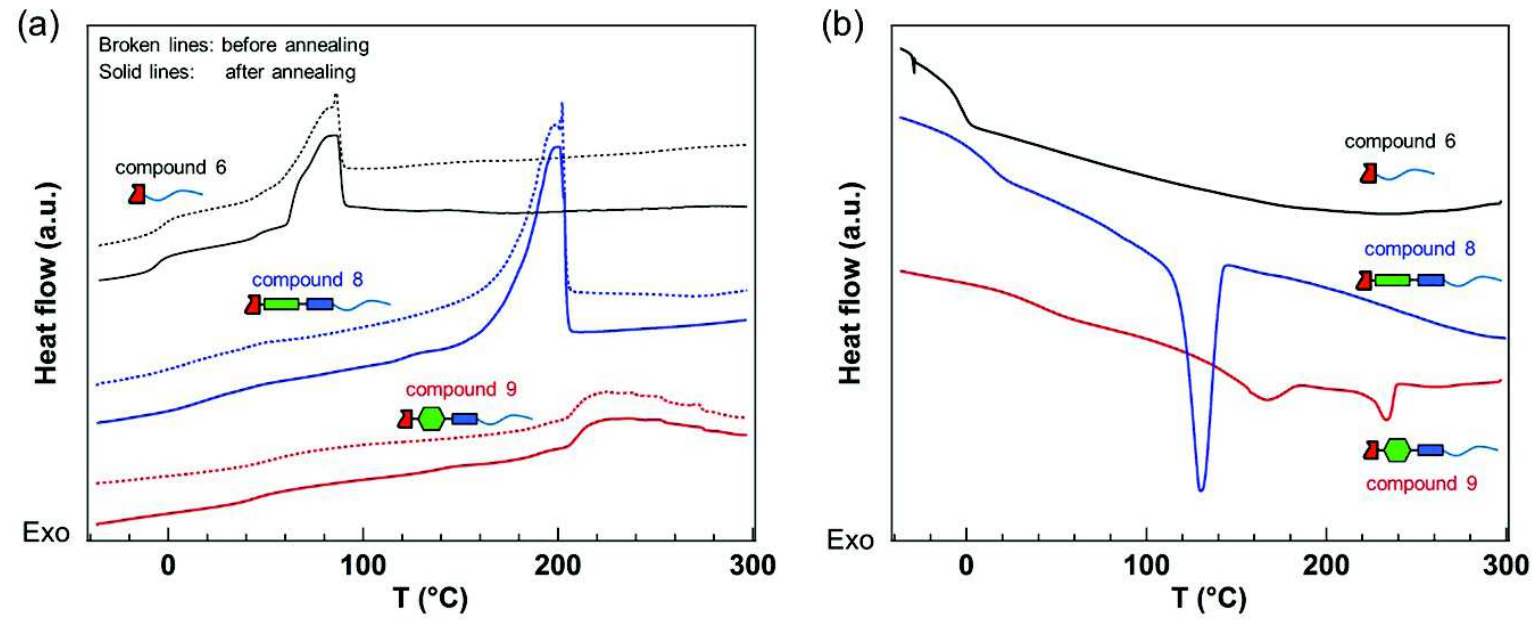

Figure S7. (a) DSC thermograms on heating for the samples before and after annealing. Broken lines represent the thermograms for the samples without annealing while solid lines indicate the ones for the samples after annealing, where the annealing was conducted at a temperature $80^{\circ} \mathrm{C}$ higher than $T_{\mathrm{g}}$. (b) DSC themograms on cooling. In both (a) and (b), black, blue, and red thermograms represent the ones of compound $\mathbf{6}$, compound $\mathbf{8}$, and compound $\mathbf{9}$, respectively. 


\section{Isothermal TGA data of final compounds}

Isothermal TGA measurements were conducted to check the degradation progress at high temperatures. The measurement temperature corresponds to the highest temperatures experienced in rheological analyses. The measurements time was 5 hours, which was sufficiently longer time scale than that of the rheological measurements.



Figure S8. Isothermal TGA data of compound 6 at $130{ }^{\circ} \mathrm{C}$ (black), compound 8 at $240{ }^{\circ} \mathrm{C}$ (blue), and compound 9 at $300{ }^{\circ} \mathrm{C}$ (red). 


\section{Variable temperature FT-IR measurements on compound 8 and compound 6}

The changes of FT-IR spectra with an increase in temperatures for compound $\mathbf{8}$ and compound 6 are shown in Figure S9 and S10, respectively. In the similar way to the changes of compound 9 described in the main text, the positions of peaks originated from $\mathrm{N}-\mathrm{H}$ and $\mathrm{C}=\mathrm{O}$ vibrations dramatically change in the vicinity of the melting point whereas the position of aliphatic $\mathrm{CH}_{2}$ vibrations arising from the alicyclic skeleton of Pripol 1009 is not affected by the temperature changes.
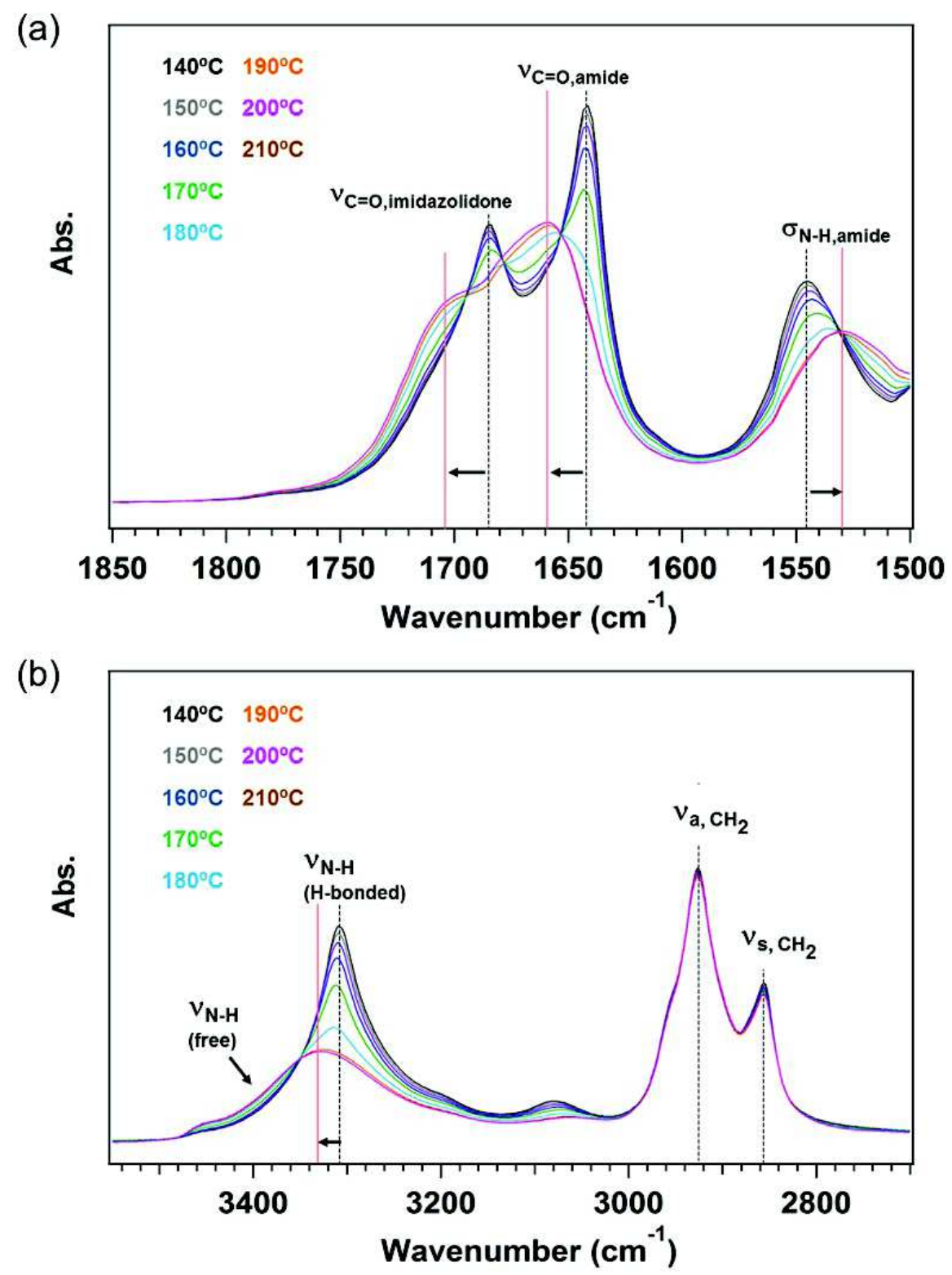

Figure S9. FT-IR spectra of compound $\mathbf{8}$ as a function of temperature (a) at the carbonyl absorption region and (b) at the high wavenumber region. The colors of spectra correspond with the measurement temperatures in the same color. In the spectra, broken black lines and red lines represent the peak positions at $140{ }^{\circ} \mathrm{C}$ and $210^{\circ} \mathrm{C}$, respectively, where arrows between the lines indicate the shift direction with an increase in temperatures. 

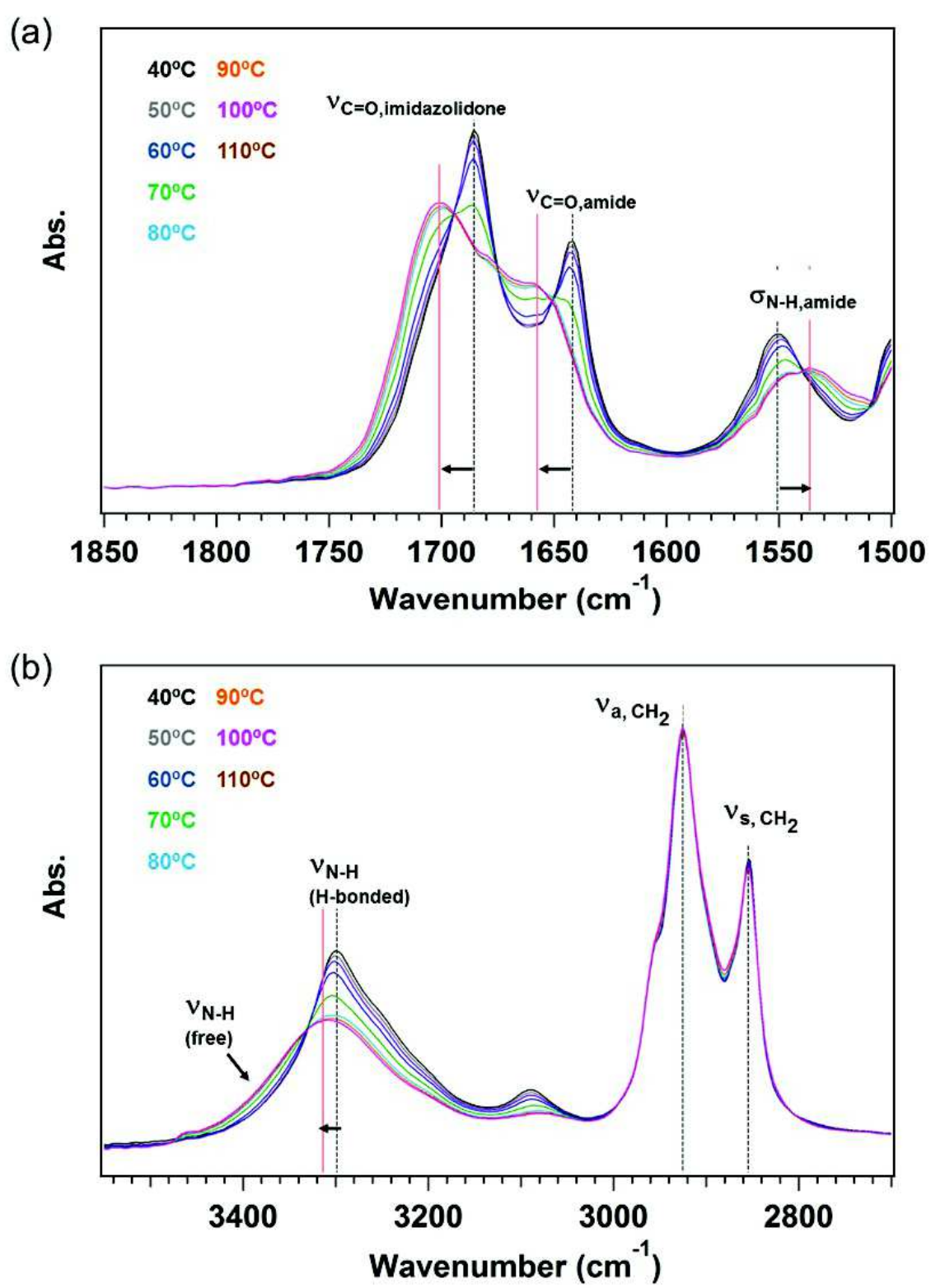

Figure S10. FT-IR spectra of compound $\mathbf{6}$ as a function of temperature at (a) the carbonyl absorption region and (b) the high wavenumber region. The colors of spectra correspond with the measurement temperatures in the same color. In the spectra, broken black lines and red lines represent the peak positions at $40{ }^{\circ} \mathrm{C}$ and $110{ }^{\circ} \mathrm{C}$, respectively, where arrows between the lines indicate the shift direction with an increase in temperatures. 


\section{Plots of $\ln \eta$ as a function of inverse temperatures}

(a)

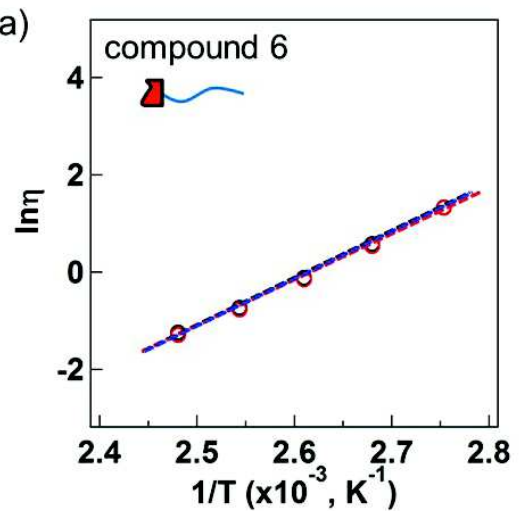

(b)

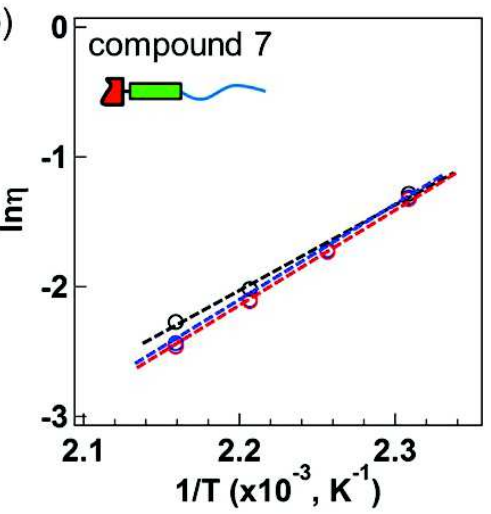

(c)

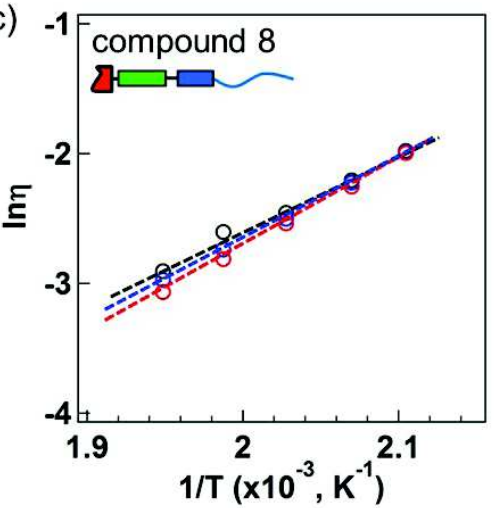

(d)

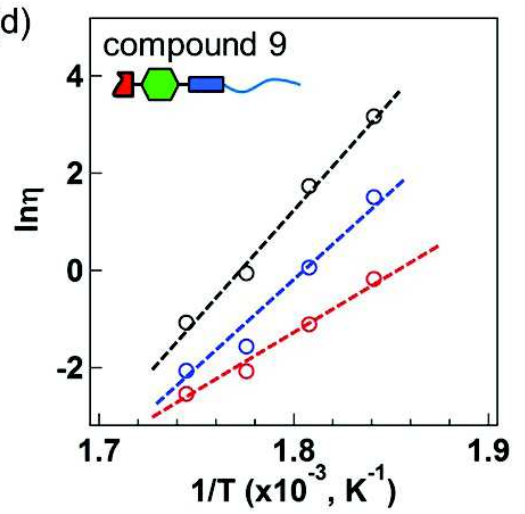

Figure S11. Plots of $\ln \eta$ as a function of inverse temperatures: (a) compound 6; (b) compound 7; (c) compound 8; (d) compound 9. The plots were made at three shear rates; $1.56 \mathrm{~s}^{-1}$ (black), $14.1 \mathrm{~s}^{-1}$ (blue), $129 \mathrm{~s}^{-1}$ (red). For compound 9, the plots were based on the data obtained by the measurements from low shear rate. 


\section{Tensile data of compound 6}

Tensile tests were performed on compound $\mathbf{6}$, using dog-bone shaped samples. To this end, rectangular plates of $1.4 \mathrm{~mm}$ thickness were prepared by pressing the molten material in a brass frame sandwitched between two non-adhesive paper sheets. After slow cooling down to room temperature, dogbone specimens of ISO 527-3 shape with working dimensions of 20 $\mathrm{mm} \times 4 \mathrm{~mm}$ were cut using a heated punch. Tensile tests were performed at room temperature using an Instron Universal Tester Model 5565 with a load cell of $100 \mathrm{~N}$ at a stretching rate of $2 \mathrm{~mm} / \mathrm{min}$. The obtained curve is shown in Figure S12a. At room temperature, compound 6 shows a Young modulus of about $25( \pm 5) \mathrm{MPa}$, an elongation at break of about $10 \%$, and the stress at break of about $2 \mathrm{MPa}$. The tensile test also revealed the occurence of the necking phenomenon, as shown in figure S12b.
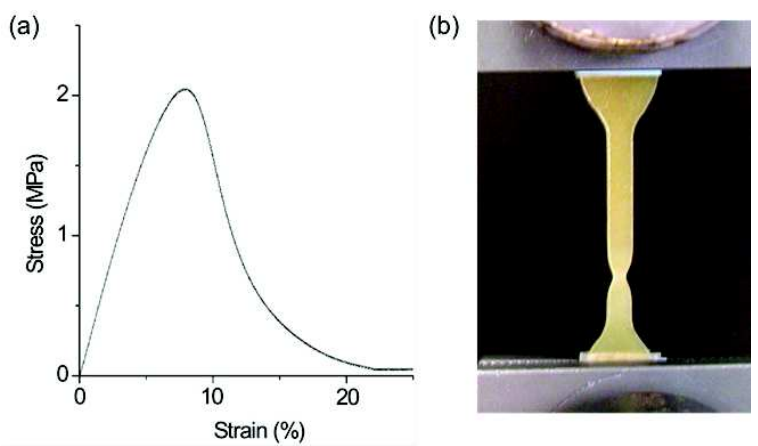

Figure S12. (a) Stress-strain curve obtained for compound 6 and (b) macroscopic image of the sample during the measurement. 
[1] R. Agnaou, M. Capelot, S. Tencé-Girault, F. Tournilhac and L. Leibler, J. Am. Chem. Soc., 2014, 136, 11268.

[2] A. M. Aerdts, K. L. L. Eersels, and G. Groeninckx Macromolecules, 1996, 29, 1041.

[3] D. B. Davies, S. F. Baranovsky, A. N. Veselkov, J. Chem. Soc., Faraday Trans. 1997, 93, 1559.

[4] E. Gentric, J. Lauransan, C. Roussel, F. A. Devillanova, G. Verani, J. Heterocyclic Chem. 1979, 16, 1083.

[5] D.W. Johnson, L.C. Palmer, T. Martin, U. Obst, J.J. Rebek, Chem. Commun., 2003, 14, 1638. 